\title{
The Areal Effects of Climate Change on the Dominant Tree Species and Associations on Kaz Mount
}

\author{
Berna Hepbilgin \\ Department of Geography, Canakkale Onsekiz Mart University \\ Terzioglu Campus, Istanbul 17020, Turkey \\ E-mail: bernahepbilgin@ comu.edu.tr
}

\begin{abstract}
Kaz Mount is a special geographical structure which has a powerful natural richness. Its natural forest area is nearly $60 \%$ of vicinity of Kaz Mount which contains the area of $1823 \mathrm{~km}^{2}$. The natural forest area of Kaz Mount has the population and associations of Pinus brutia, Pinus nigra, Quercus, Abies, Fagus and Castanea. It is investigated in this study that how the dominant tree species and associations of Kaz Mount will be effected by Climate Change areally. It is used the digital data of Forest Management Plans and the annual temperature and precipitation of Kaz Mount and the methods in Mapinfo Professional 2017 program. It is also used Erinç and Emberger Climate Classifications. Results generally showed that per-humid and humid climatic conditions were replaced by semi-humid and semi-arid climate conditions in the dominant tree populations and associations of Kaz Mount within the range of 2016-2040; 20412070 and 2071-2099 according to GFDL-ESM-2M projection and the scenarios of RCP 4.5 and RCP 8.5.
\end{abstract}

Keywords: Kaz Mount, Tree Species, Associations, Forest, Climate Change.

DOI: $10.7176 / \mathrm{JSTR} / 6-04-08$

\section{Özet}

Kaz Dağı, önemli doğal zenginliğe sahip özel bir coğrafi yapıdır. Kaz Dağı'nın doğal orman alanı, yaklaşık 1823 km2 kapsayan yakın çevresinin yaklaşık \%60'ını oluşturur. Kaz Dağı'nın doğal orman alanı Pinus brutia, Pinus nigra, Quercus, Abies, Fagus and Castanea saf ağaç toplulukları ve egemen birliklerini içerir. Bu çalışmada bu baskın ağaç toplulukları ve birliklerin iklim değişikliğinden alansal olarak nasıl etkilendiği araştırılmaktadır. Kaz Dağı'na ait sayısal Orman Amenajman Planları, yıllık sıcaklık ve yağış ortalamaları bu çalışmada temel veri olarak, Mapinfo Professional 2017 CBS programı içerisindeki sorgulamalar yöntem olarak kullanılmıştır. Ayrıca Erinç ve Emberger iklim sınıflandırmaları kullanılmıştır. Sonuçlar genel olarak, GFDL-ESM-2M projeksiyonu ve RCP 4.5 ve RCP 8.5 senaryoları için 2016-2040; 2041-2070 ve 2071-2099 yıl aralıklarında Kazdağı baskın ağaç toplulukları ve birliklerinde çok nemli ve nemli iklim koşullarının yarı nemli ve yarı kurak iklim koşullarına dönüştüğünü göstermektedir.

Keywords: Kaz Dağı, Ağaç Türleri, Birlikler, Orman, İklim Değişikliği

\section{Giriş}

Kazdağ1 1774 metre yüksekliğe sahip, zengin biyolojik çeşitliliği ile bulunduğu bölgede önemli bir doğal coğrafi unsurdur (Şekil 1). Kazdağı ve yakın çevresini kapsayan 1823 km²'lik alanın yaklaşık \%60'ını doğal orman alanı oluşturur. Kazdağı doğal orman alanında yaygın olarak kızılçam (Pinus brutia), karaçam (Pinus nigra), meşe (Quercus), göknar (Abies), kestane (Castanea) ve kayın (Fagus) saf topluluklar ve birlikler halinde bulunmaktadır. Bu çalışmada Kazdağı'ndaki saf ağaç topluluklarının ve egemen birliklerin iklim değişikliği projeksiyon senaryolarından elde edilen modellere göre 2016-2099 y1lları arasında üç periyottaki (2016-2040, 2040-2070, 2070-2099) alansal iklim değişimlerine dair öngörüler elde edilmiştir. Yazarın daha önceki çalışmasında Kazdağı'nda kurakçıl nemcil ve kurak-nemli geçişinde değerlendirilebilecek ağaç türleri gruplandırılarak bu grupların iklim değişikliği açısından alansal değişimleri sorgulanmıştı (Hepbilgin \& Koç, 2019b). Bu çalışmada ise yukarıda bildirilen periyotlar için Kazdağı'nın kızılçam, karaçam gibi saf yayılışlı ağaç toplulukları ile egemen birliklerinde hakim iklim tiplerindeki alansal değişimlere dair öngörüler elde edilmiştir. 
Şekil 1. Kazdağı Lokasyon Haritası

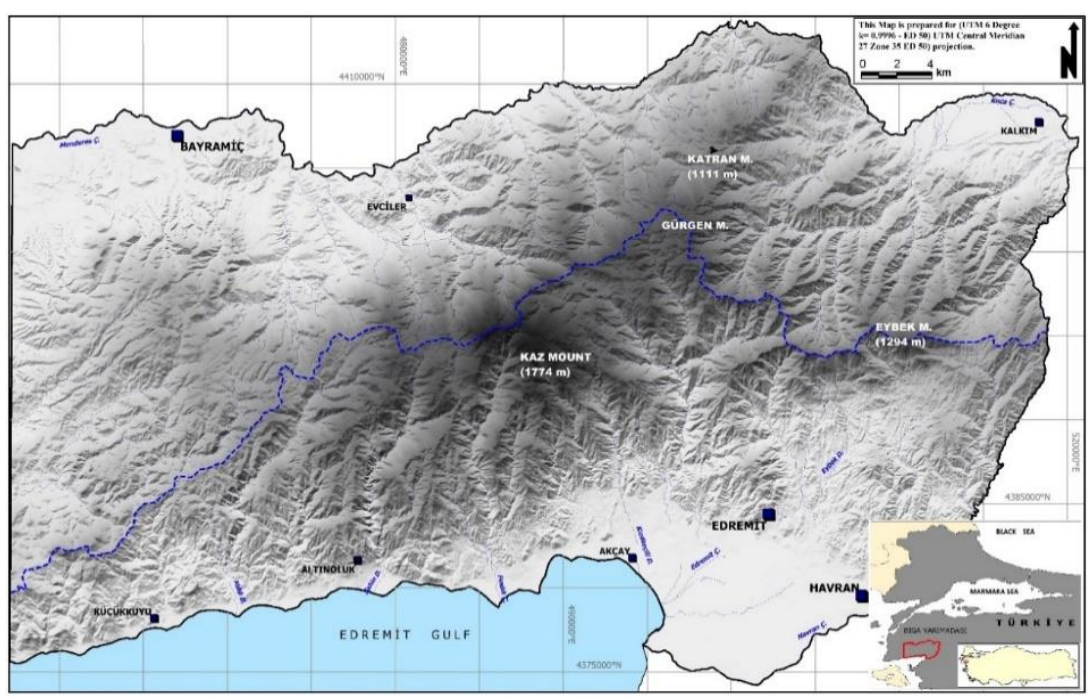

İklim Değişikliğinin ağaç türleri üzerindeki etkilerinin incelendiği çeşitli çalışmalara ulaşılmıştır. Zeydanlı ve ark. (2010) Seyhan havzasında kızılçam, karaçam, göknar ve sedir yayılışlarına iklim değişikliğinin öngörülen etkilerini inceledikleri çalışmalarında 2050 yılına gelindiğinde, kızılçam meşcerelerinin \%56,2'sinin; karaçam meşcerelerinin \%68,5'inin; göknar meşcerelerinin \%85,7'sinin ve sedir meşcerelerinin \%93,1'inin bu türlerin yaşamı için uygun olmayacağını öngörmüşlerdir. Labourdette ve ark. (2012), iklim değişikliğinin Akdeniz dağlarındaki orman formasyonuna etkisini inceledikleri çalışmada, Akdeniz ağaçlarının komünitelerinde yukarı yönlü bir göç, soğuğa adapte olmuş ağaçlarda ve 1lıman komünitelerde azalma elde etmişlerdir. Çalışmada ayrıca, en büyük değişikliğin nispeten alçak kesimlerdeki Akdeniz ağaç türlerinin yaşam alanlarındaki genişleme olduğu sonucuna varılmıştır. Boulangeat ve ark. (2014) tarafindan, iklim ve arazi örtüsü değişikliğine karşı vejetasyon yapısı ve bitki farklılaşmasının araştırıldığı çalışmada zamansal ölçek 2020, 2050 ve 2080 olarak belirlenmiş ve orman örtüsü dağılım aralığında yavaş gelişen bir yukarı yönlü kayma elde edilmiştir. Cannone (2014), iklimdeki ısınmaya karşı bitki türlerinin ve komünitelerin ekolojik tepkilerini araştırdığı çalışmasında dayanıklı türlerin üçte birinde azalma saptamış, bu durumun bu türler için bir yok olma işareti olabileceğini belirtmiştir. Bu yüzden bitki komünitelerinin varlığının, doğal türlerin sebat/dayanıklılığına ve uygun ekolojik aralıkları doldurma yeteneklerine bağlı olduğunu belirtmiştir. Lin ve ark. (2014) iklim değişikliği'nin Tayvan'da endemik ve tehlike altında olan iki yüksek dağ ağaç türüne (Abies ve Tsuga) etkisini araştırdıkları çalışmada, iklim değişikliği nedeniyle dağlık ve alpin habitat türlerinde yukarı yönlü bir kayma tespit etmişlerdir. Koo ve ark. (2017) tarafından Kore yarımadasındaki ağaç dağılışına iklim değişikliğinin potansiyel etkilerinin incelendiği çalışmada Silver magnolia'nın bütünleşik tür dağılım modelleri ile türün gelecekteki öngörülen dağılışının açık bir şekilde değiştiği belirtilmiştir. Ayrıca, tür dağılım modelleri RCP 8.5 senaryosuna göre 2050 ve 2070 'de maksimum alan genişlemesi öngörmüştür. Koç ve İkiel (2017), Trakya'da vejetasyon süreleri ve değişimleri üzerine yaptıkları çalışmada, vejetasyon sürelerinde 1990'lı yıllardan itibaren artma eğilimi olduğunu, vejetasyon sürelerinin başlangıç ve bitiş tarihleri arasındaki farkın giderek arttığını, vejetasyon süresinin giderek uzadığını, vejetasyon döneminin daha erken başlayıp daha geç bittiğini tespit etmişlerdir. Şar, T ve ark. (2018) iklim değişikliği iyimser ve kötümser senaryolarına göre, İç Batı Anadolu Bölümü'nde günlük ortalama sıcaklıklara göre vejetasyon dönemindeki değişimi araştırdıkları çalışmalarında, sahanın kuzeyinden güneyine ve doğusundan batısına vejetasyon devresinin uzadığı sonucunu elde etmişlerdir. Buras ve Menzel (2019), 2061-2090 periyodu için iklim değişikliğinin Avrupa'da en yaygın 26 ağaç türüne etkisini RCP 4.5 ve RCP 8.5 senaryolarına göre inceledikleri çalışmalarında, tür çeşitliliğinin Akdeniz ve Orta Avrupa alçak kesimlerinde azalırken, İskandinavya ve Orta Avrupa yüksek kesimlerinde arttığını; ele alınan lokasyonların iyimser ve kötümser senaryoya göre, sırasıyla \%76 ve \%80'inde ağaç türlerinin bolluğunda lokal olarak azalma ve yine aynı sırayla \%74 ve \%68'inde ağaç türlerinin çeşitliliğinde artış olduğu sonucuna ulaşmışlardır. Mert, A ve ark. (2019) Türkiye saçlı meşe'sinin (Quercus cerris L.) potansiyel dağılışında iklim değişikliğinin etkilerini araştırdıkları çalışmalarında, Kocadağ' 'n güney ve batı kesiminde bu türün varlığ 1 için iklimin bu yüzyıl sonunda uygun olmayacağ

$60 \mid \mathrm{P}$ a g e

www.iiste.org 
sonucuna ulaşmışlardır.

$\mathrm{Bu}$ çalışmada, Kazdağı'ndaki saf ağaç toplulukları ve egemen ağaç birliklerinin, GFDL-ESM-2M projeksiyonu iyimser (RCP 4.5) ve kötümser senaryo (RCP 8.5) verilerine göre, 1970-2000 referans dönemi iklim tipleri baz alınarak, 2016-2040, 2041-2070 ve 2071-2099 projeksiyon dönemlerindeki iklim tiplerinde meydana gelecek değişim alansal olarak araştırılmıştır. Elde edilen bulguların Kazdağ 1 yaygın ağaç türleri veya egemen birlikleri üzerine yapılabilecek sonraki daha detaylı ekocoğrafik çalışmalara temel oluşturması beklenmektedir.

\section{Yöntem}

Kazdağ çevresindeki meteoroloji istasyonlarından Bergama, Ayvalık, Bozcaada, Burhaniye, Edremit, Balıkesir, Gönen ve Çanakkale'ye (Hepbilgin, 2018) ait temelde yıllık ortalama sıcaklık ve yıllık toplam yağış verilerine dayandırılan bu çalışmada, iklim değiş̧ikliği projeksiyonlarına yönelik 2016-2040, 20412070 ve 2071-2099 yıl aralı̆̆ için oluşturulmuş olan Erinç ve Emberger iklim sınıflandırmalarına ait iklim modelleri ve Orman Genel Müdürlüğ̈̈’nden temin edilmiş olan sayısal Orman Amenajman Planları kullanılmıştır. Sayısal Orman Amenajman Planlarındaki saf yayılışlı ağaç toplulukları ve egemen birlik alanları Mapinfo Professional 2017 CBS programında sorgulamalar yardımıyla çıkartılıp birleştirilerek saf yayılan ağaç toplulukları ve egemen birlik alanlarını içeren sayısal Kazdağ 1 doğal orman alanı oluşturulmuştur. Ardından iklim değişikliği senaryolarına ilişkin yazarın Kazdağı iklim değişikliğine yönelik önceki çalışmalarında elde edilmiş olan 2040, 2070 ve 2099 yıllarına ait Erinç (Erinç, 1984) ve Emberger (Akman, 1990) iklim tipleri (Hepbilgin \& Koç, 2018) saf topluluklar ve egemen birlik alanları (Tablo 1) (Hepbilgin \& Koç, 2019a) ile alansal olarak çakıştırılarak ilgili yıllarda kaybettikleri ya da kazandıkları alanlar $\left(\mathrm{km}^{2}\right)$ elde edilmiştir. Son işlem olarak, saf yayılışlı ağaç toplulukları ve egemen birlik alanlarındaki dönemsel değişimler ve Referans Dönemindeki (1970-2000) alanlarına göre değişim yüzdeleri elde edilerek sonuçlar değerlendirilmiştir.

Tablo 1. Kazdağı'nda Egemen Ağaç Türleri ve Birlikleri ile Kısaltmaları

\begin{tabular}{|c|c|c|c|}
\hline Egemen cins/tür & Kisaltma & Egemen cins/tür & Kisaltma \\
\hline $\begin{array}{l}\text { Pinus nigra - Castanea (Karaçam-Kestane) } \\
\text { Pinus nigra - Other leafed trees (Karaçam-Diğer } \\
\text { Yapraklilar) } \\
\text { Pinus nigra - Fagus (Karaçam-Kayın) } \\
\text { Pinus nigra - Quercus (Karaçam-Meşe) }\end{array}$ & $\begin{array}{l}\text { ÇkDy } \\
\text { ÇkKn } \\
\text { ÇkM }\end{array}$ & $\begin{array}{l}\text { Fagus - Castanea (Kayın-Kestane) } \\
\text { Fagus - Pinus nigra (Kayın-Karaçam) } \\
\text { Fagus - Abies (Kayın-Göknar) } \\
\text { Fagus - Quercus (Kayın-Meşe) }\end{array}$ & $\begin{array}{l}\text { KnKs } \\
\text { KnÇk } \\
\text { KnG } \\
\text { KnM } \\
\end{array}$ \\
\hline $\begin{array}{l}\text { Pinus nigra - Pinus brutia (Karaçam-Kızılçam) } \\
\text { Pinus nigra - Abies (Karaçam-Göknar) } \\
\text { Pinus nigra - Maquis (Karaçam-Maki) }\end{array}$ & $\begin{array}{l}\text { ÇkÇz } \\
\text { ÇkG } \\
\text { ÇkMa }\end{array}$ & $\begin{array}{l}\text { Castanea - Fagus (Kestane-Kayın) } \\
\text { Castanea - Pinus nigra (Kestane-Karaçam) } \\
\text { Castanea - Quercus (Kestane-Meşe) }\end{array}$ & $\begin{array}{l}\mathrm{KsKn} \\
\mathrm{KsÇ} \\
\mathrm{KsM}\end{array}$ \\
\hline $\begin{array}{l}\text { Quercus - Other leafed trees (Meşe-Diğer } \\
\text { Yapraklilar) }\end{array}$ & MDy & $\begin{array}{l}\text { Other leafed trees - Pinus nigra (Diğer } \\
\text { Yapraklilar-Karaçam) }\end{array}$ & DyÇk \\
\hline Quercus - Abies (Meşe-Göknar) & MG & Maquis (Maki) & Ma \\
\hline Quercus - Fagus (Meşe-Kayın) & $\mathrm{MKn}$ & Other leafed trees (Diğgr Yapraklular) & Dy \\
\hline Quercus - Castanea (Meşe-Kestane) & MKs & Abies (Göknar) & G \\
\hline Quercus - Pinus nigra (Meşe-Karaçam) & MÇk & Castanea (Kestane) & Ks \\
\hline Quercus - Pinus brutia (Meşe-Kızılçam) & $\mathrm{MÇz}$ & Fagus (Kayın) & $\mathrm{Kn}$ \\
\hline Abies - Fagus (Göknar-Kayın) & GKn & Quercus (Meşe) & M \\
\hline Abies - Pinus nigra (Göknar-Karaçam) & GÇk & Pinus nigra (Karaçam) & Çk \\
\hline Pinus bruita - Pinus nigra (Kızılçam-Karaçam) & ÇzÇk & Pinus brutia (Kızılçam) & Çz \\
\hline $\begin{array}{l}\text { Pinus brutia - Quercus (Kızılçam-Meşe) } \\
\text { Pinus brutia - Other leafed trees (Kızılçam-Diğer } \\
\text { Yapraklılar) }\end{array}$ & $\begin{array}{l}\text { ÇzM } \\
\text { ÇzDy }\end{array}$ & Pinus pinea (Fıstıkçamı) & Çk \\
\hline
\end{tabular}

\section{Karaçam (Pinus nigra) Birlikleri}

Kazdağı''nda Karaçam (Pinus nigra); kestane (Castanea), kayın (Fagus), meşe (Quercus), göknar (Abies), kızılçam (Pinus brutia) ve Maki ile birlik oluşturmaktadır. Bu birlikler içerisinde kestane, kayın, meşe, göknar ve kızılçam ile birlik oluşturan karaçam alanlarında dikkate değer alansal değişimler elde edilmiştir. Gerek karaçam birlikleri gerekse de Kazdă̆g'ndaki yukarıda belirtilen yaygın ağaç türlerine ait diğer baskın birlikler, içerisinde daha az oranda diğer bazı ağaç türlerini de içerir (Hepbilgin, 2019c).

\subsection{Karaçam-Kestane (Pinus nigra - Castanea) Egemen Birliği:}

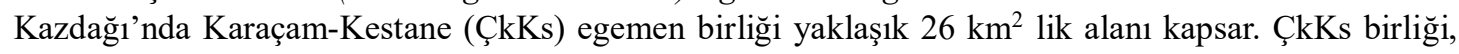

$61 \mid P$ a g e

www.iiste.org 
Kazdağı'nın kuzey yamacında 327 m. ile 1336 m. arasında; güney yamaçta, 597 m. ile 1333 m. arasında bulunur (Hepbilgin \& Koç, 2019a). Bu birlik alanı içerisinde, yer yer Kayın, Göknar ve Meşe (Q.frainetto)'ye de rastlanır (Hepbilgin, 2019c). Karaçam-Kestane ormanlarında, Erinç iklim sınıflandırmasına göre, referans dönemde ağırlıklı olarak nemli, küçük oranda da yarı nemli iklim koşulları hakimdir (Tablo 2). Karaçam-Kestane ormanlarının bulunduğu alan için referans yıldan (2000) itibaren 2099'a doğru her iki senaryoda da (RCP 4.5 ve RCP 8.5) nemli iklim koşullarından yarl-nemli iklim koşullarına doğru bir değişim elde edilmiştir (Tablo 2). İyimser senaryoya (RCP 4.5) göre, 2000 yılında birlik alanının $21.2 \mathrm{~km}^{2}$ 'si nemli iklim koşullarında iken 2099' da bu alan $7.9 \mathrm{~km}^{2}$ 'ye düşmüştür. Yine, 2000 yılında birlik alanının 4.6 km²'si yarı-nemli iklim koşullarında iken 2099 yılında bu iklim koşulları $20.1 \mathrm{~km}^{2}$ 'ye genişlemiştir (Tablo 2). Değişim yüzdeleri incelendiğinde her iki senaryoda da referans dönem ile projeksiyon dönemleri arasında nemli iklim koşulları artan oranda etkisini kaybederken, yarı nemli iklim koşullarının özellikle 2040 yılından sonra değişim oranı azalsa da egemenliğini sürdürdüğü değerlendirmesi yapılabilir. Dönemlerin kendi içindeki değişimleri incelendiğinde, en önemli değişim 2040-2070 aralığında gözlenmektedir (Tablo 2).

Tablo 2. Karaçam-Kestane (Pinus nigra - Castanea) Egemen Birliğinde Alansal İklim Değişimleri

\begin{tabular}{|c|c|c|c|c|c|c|c|}
\hline \multicolumn{5}{|c|}{ Pni-Cas (ÇkKs) } & \multirow{2}{*}{\multicolumn{3}{|c|}{ RCP 8.5}} \\
\hline \multicolumn{5}{|c|}{ RCP 4.5} & & & \\
\hline & Y1l Aralığg & $\begin{array}{l}\text { Çok } \\
\text { Nemli }\end{array}$ & Nemli & Yar1-nemli & Çok Nemli & Nemli & Yar1-Nemli \\
\hline \multirow{4}{*}{$\mathrm{km}^{2}$} & $1970-2000(\mathrm{RfD})$ & 2,1 & 21.20 & 4.60 & 2,1 & 21.20 & 4.60 \\
\hline & $2016-2040$ & 0.60 & 17.60 & 9.80 & 2.40 & 20.20 & 5.80 \\
\hline & $2041-2070$ & 0.08 & 12.60 & 15.40 & 0.30 & 14.80 & 12,9 \\
\hline & $2071-2099$ & 0.00 & 7.90 & 20.10 & 0.00 & 3.30 & 24.80 \\
\hline \multirow{3}{*}{ 苂 } & RfD-2040 & - & -17 & 113 & - & -5 & 26 \\
\hline & RfD-2070 & - & -28 & 57 & -88 & -27 & -78 \\
\hline & RfD-2099 & - & -37 & 31 & -100 & -78 & 1808 \\
\hline \multirow{3}{*}{ 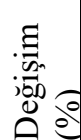 } & $2040-2070$ & -87 & -315 & 462 & - & -243 & 5 \\
\hline & $2040-2099$ & - & 67 & -49 & - & 467 & -397 \\
\hline & $2070-2099$ & - & 31 & -47 & 14 & 191 & -2430 \\
\hline
\end{tabular}

Emberger İklim Sınıflandırmasına göre Karaçam-Kestane Birliğinde önemli değişim ilk projeksiyon döneminde (2016-2040) gözlenmektedir. Birlik alanı için, her iki senaryoya göre de Referans Dönemde Az Yağışlı Akdeniz iklimi egemen iken, 2040 yılında ve sonraki dönemlerde Yağışlı Akdeniz iklimi egemen olmuştur (Tablo 3).

Tablo 3. Karaçam - Kestane (Pinus nigra - Castanea) Egemen Birliğinde Alansal İklim Değişimleri

\begin{tabular}{|c|c|c|c|c|c|c|c|}
\hline \multicolumn{5}{|c|}{ Pni-Cas (ÇkKs) } & \multirow{2}{*}{\multicolumn{3}{|c|}{ RCP 8.5}} \\
\hline \multicolumn{5}{|c|}{ RCP 4.5} & & & \\
\hline & Y1l Aralığ & AzYağ.Akd & Yağ.Akd. & YarıKurAkd & AzYağAkd & YağAkd. & YarıKurAkd \\
\hline \multirow{4}{*}{$\mathrm{km}^{2}$} & 1970-2000 RfD) & 25,50 & 2,50 & 0,03 & 25,50 & 2,50 & 0,03 \\
\hline & 2016-2040 & 0,01 & 28,10 & 0,00 & 0,00 & 28,10 & 0,00 \\
\hline & $2041-2070$ & 0,05 & 28,00 & 0,00 & 0,01 & 28,10 & 0,00 \\
\hline & 2071-2099 & 0,44 & 27,60 & 0,00 & 4,30 & 23,70 & 0,00 \\
\hline \multirow{6}{*}{ 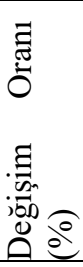 } & RfD-2040 & -100 & 1024 & -100 & -100 & 1024 & -100 \\
\hline & RfD-2070 & -100 & 1020 & -100 & -100 & 1024 & -100 \\
\hline & RfD-2099 & -98 & 1004 & -100 & -83 & 848 & -100 \\
\hline & $2040-2070$ & 525 & 0 & - & - & 0 & - \\
\hline & 2040-2099 & 5400 & -2 & - & - & -16 & - \\
\hline & 2070-2099 & 780 & -1 & - & 47678 & -16 & - \\
\hline
\end{tabular}

\subsection{Karaçam-Kayın (Pinus nigra - Fagus) Egemen Birliği (ÇkKn)}

Karaçam-Kayın (ÇkKn) Birliği Kazdağı'nda 29 km² civarında bir alan kaplar. Karaçam ve Kayın'ın egemen olduğu bu birlik içerisinde yer yer Meşe (Q.frainetto), Kestane ve Göknar bulunur (Hepbilgin, 2019c). Karaçam-Kayın ormanları Kazdağı kuzey yamacında 135 m-1358 m; güney yamacında ise 558

$62 \mid \mathrm{P}$ a g e

www.iiste.org 
m-1421 m arasında yayılır (Hepbilgin \& Koç, 2019a). Karaçam-Kayın ormanlarında, Erinç İklim sınıflandırmasına göre her iki senaryo için de çok nemli iklimden yarı nemli iklime doğru bir değişim söz konusudur (Tablo 4). Bununla birlikte iyimser senaryoya göre 2099 yılına gelindiğinde Karaçam-Kayın birliğinde yarı nemli iklim etkisini genişletse de egemen iklim tipi nemli iklim iken kötümser senaryoya göre hakim iklim tipi yarı nemli olarak elde edilmiştir (Tablo 4). Ayrıca, her iki senaryoya göre de 20712099 döneminde, küçük bir oranda yarı kurak iklimin geliştiği de gözlenmektedir (Tablo 4).

Tablo 4. Karaçam - Kayın (Pinus nigra - Fagus) Egemen Birliğinde Alansal İklim Değişimleri

\begin{tabular}{|c|c|c|c|c|c|c|c|c|c|}
\hline \multicolumn{6}{|c|}{ Pni-Fag (CKkKn) } & & & & \\
\hline \multicolumn{6}{|c|}{ RCP 4.5} & \multicolumn{4}{|c|}{ RCP 8.5} \\
\hline & Y1l Aralığ & $\begin{array}{l}\text { Çok } \\
\text { Nemli }\end{array}$ & Nemli & $\begin{array}{l}\text { Yar1 } \\
\text { Nemli }\end{array}$ & $\begin{array}{l}\text { Yar1 } \\
\text { Kurak }\end{array}$ & $\begin{array}{l}\text { Çok } \\
\text { Nemli }\end{array}$ & Nemli & $\begin{array}{l}\text { Yar1 } \\
\text { Nemli }\end{array}$ & $\begin{array}{l}\text { Yar1 } \\
\text { Kurak }\end{array}$ \\
\hline \multirow[b]{4}{*}{$\mathrm{km}^{2}$} & $1970-2000$ (RfD) & 8,84 & 18,50 & 1,80 & & 8,84 & 18,50 & 1,80 & \\
\hline & 2016-2040 & 4,80 & 20,21 & 4,16 & & 9,34 & 17,60 & 2,14 & \\
\hline & 2041-2070 & 0,99 & 20,54 & 7,63 & & 3,49 & 19,60 & 6,02 & \\
\hline & 2071-2099 & 0,03 & 18,15 & $\mid 10,99$ & 0,0001 & & 12,90 & 16,24 & 0,0003 \\
\hline \multirow{3}{*}{ 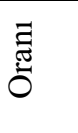 } & RfD-2040 & -46 & 1022 & 131 & & 6 & -5 & 19 & \\
\hline & RfD-2070 & -79 & 2 & 84 & & -63 & 11 & 181 & \\
\hline & RfD-2099 & -97 & -12 & 44 & & -100 & -34 & 170 & \\
\hline \multirow{3}{*}{ 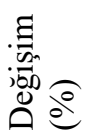 } & $2040-2070$ & -79 & 2 & 84 & & -63 & 11 & 181 & \\
\hline & $2040-2099$ & 73 & -100 & -36 & & -1207 & -334 & 860 & \\
\hline & $2070-2099$ & 22 & -803 & -47 & & 60 & -401 & -6 & \\
\hline
\end{tabular}

Sahada, Emberger İklim Sınıflandırmasına göre, her iki senaryoda da Referans Döneminde birbirine yakın alansal büyüklüklerde $A z$ Yağışlı Akdeniz ve Yağışlı Akdeniz iklim tipi görülürken, 2040-2099 sürecinde Karaçam-Kayın ormanlarının tamamında Yağışlı Akdeniz iklimi egemen olmuştur (Tablo 5).

Tablo 5. Karaçam - Kayın (Pinus nigra - Fagus) Egemen Birliğinde Alansal İklim Değişimleri

\begin{tabular}{|c|c|c|c|c|c|c|c|}
\hline \multicolumn{5}{|c|}{ Pni-Fag (ÇkKn) } & \\
\hline \multicolumn{5}{|c|}{ RCP 4.5} & \multicolumn{2}{|r|}{ RCP 8.5} & \\
\hline & Y1l Aralığ & AzYağAkd & YağAkd & YarıKurAkd & AzYağAkd & YağAkd & YarıKurAkd \\
\hline \multirow{4}{*}{$\mathrm{km}^{2}$} & 1970-2000 (RfD) & 19 & 10 & 0 & 19,20 & 9,87 & 0 \\
\hline & \begin{tabular}{|l|}
$2016-2040$ \\
\end{tabular} & 0 & 29 & - & 0,00 & 29,16 & - \\
\hline & 2041-2070 & 0 & 29 & - & 0,00 & 29,10 & - \\
\hline & 2071-2099 & 0 & 29 & - & 1,58 & 27,50 & - \\
\hline \multirow{3}{*}{ 茜 } & RfD-2040 & -100 & 195 & - & -100 & 195 & - \\
\hline & RfD-2070 & -100 & 195 & - & $\mid-100$ & 195 & - \\
\hline & RfD-2099 & -100 & 195 & - & -92 & 179 & - \\
\hline \multirow{3}{*}{ 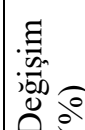 } & $2040-2070$ & - & 0 & - & 0 & 0 & - \\
\hline & 2040-2099 & - & 0 & - & - & -6 & - \\
\hline & $2070-2099$ & - & 0 & - & - & -5 & - \\
\hline
\end{tabular}

\subsection{Karaçam-Meşe (Pinus nigra-Quercus) Egemen Birliği:}

Karaçam-Meşe (ÇkM) birliği Kazdağı'nda yaklaşık $29 \mathrm{~km}^{2}$ 'lik bir alana sahiptir. Bu birlik içerisinde meşe türlerinden çoğunlukla macar meşesi (Q.frainetto) bulunur (Hepbilgin, 2019c). ÇkM birliği, kuzey yamaçta 249m-1366m; güney yamaçta 263-1660 m arasında yayllır (Hepbilgin \& Koç, 2019a). Karaçam-Meşe ormanlarının yaklaşık yarısı kuzey yamaçta 500-750 m arasında bulunurken, güney yamaçta, 750m-1000m arasında yoğunlaşır (Hepbilgin \& Koç, 2019a). Referans Dönemde, KaraçamMeşe ormanlarının yaklaşık $83 \mathrm{~km}^{2}$ 'si nemli iklim, $73 \mathrm{~km}^{2}$ 'si yarı nemli iklim, yaklaşı $10 \mathrm{~km}^{2}$ 'si ise çok nemli iklim etkisindedir (Tablo 6). İyimser senaryoya (RCP 4.5) göre, yıl aralıklarındaki değişim oranları desenine göre bir değerlendirme yapıldığında, Karaçam-Meşe ormanlarının küçük bir bölümünde etkili olan çok nemli iklim koşullarının 2099 yılına gelindiğinde ortadan kalktığı söylenebilir. Yine, nemli iklim koşulları 2099 yılına doğru sahadaki etkisini \%63 oranında kaybederken, sahanın büyük kesiminde yarı nemli iklim koşulları hakim (\%84) duruma geçmiştir (Tablo 6). Kötümser senaryo (RCP 8.5) için de 
benzer, fakat daha belirgin bir değişim deseni görülmektedir (Tablo 6).

Tablo 6. Karaçam - Meşe (Pinus nigra - Quercus) Egemen Birliğinde Alansal İklim Değişimleri

\begin{tabular}{|c|c|c|c|c|c|c|c|c|c|}
\hline \multicolumn{6}{|c|}{ Pni-Qu (ÇkM) } & & & & \\
\hline \multicolumn{6}{|c|}{ RCP 4.5} & \multicolumn{3}{|c|}{ RCP 8.5} & \\
\hline \multicolumn{3}{|c|}{ Yıl Aralığı|Çok } & Nemli & \begin{tabular}{|l} 
Yar1 \\
Nemli
\end{tabular} & \begin{tabular}{|l|} 
Yar1 \\
Kurak
\end{tabular} & $\begin{array}{l}\text { Çok } \\
\text { Nemli }\end{array}$ & Nemli & $\begin{array}{l}\text { Yar1- } \\
\text { Nemli }\end{array}$ & $\begin{array}{l}\text { Yar1- } \\
\text { Kurak }\end{array}$ \\
\hline \multirow{4}{*}{$\mathrm{km}^{2}$} & $1970-2000$ (RfD) & 9,77 & 82,90 & 73,14 & & 9,77 & 82,90 & 73,10 & \\
\hline & 2016-2040 & 3,18 & 66,83 & 95,85 & - & 10,50 & 78,10 & 77,16 & \\
\hline & 2041-2070 & 0,74 & 46,19 & 118,94 & - & 1,80 & 55,60 & 108,40 & \\
\hline & 2071-2099 & 0,30 & 30,66 & 134,85 & & 0,18 & 13,00 & 152,12 & 0 \\
\hline \multirow{3}{*}{ 敬 } & RfD-2040 & -67 & -19 & 31 & & 7 & -6 & 6 & \\
\hline & RfD-2070 & -92 & -44 & 63 & & -82 & -33 & 48 & \\
\hline & RfD-2099 & -97 & -63 & 84 & & -98 & -84 & 108 & \\
\hline \multirow{3}{*}{ 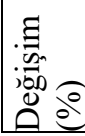 } & $2040-2070$ & -77 & -31 & 24 & & -83 & -29 & 40 & \\
\hline & 2040-2099 & -91 & -54 & 41 & & -98 & -83 & 97 & \\
\hline & 2070-2099 & -59 & -34 & 13 & & -90 & -77 & 40 & \\
\hline
\end{tabular}

Emberger İklim Sınıflandırması bulgularına göre ise, her iki senaryoda da Karaçam-Meşe ormanlarının büyük bölümünde (152 km²) Referans Döneminde (1970-2000) Az Yağışl Akdeniz iklimi etkili iken, 2099 yılı periyodunda Yağışlı Akdeniz iklimi hakim duruma geçmiştir (Tablo 7). Emberger iklim tipleri içerisinde 2000-2040 yılları arasında Az Yağışlı Akdeniz iklimi neredeyse tamamen etkisini Yağışı Akdeniz iklimine bırakmıştır (Tablo 7). 2040 yılından sonra her iki senaryo için de tekrar eski koşullara (Az Yağış̧1 Akdeniz) dönme eğilimi görülmektedir (Tablo 7).

Tablo 7. Karaçam - Meşe (Pinus nigra - Quercus) Egemen Birliğinde Alansal İklim Değişimleri

\begin{tabular}{|c|c|c|c|c|c|c|c|}
\hline \multicolumn{5}{|c|}{ Pni-Qu (ÇkM) } & \multirow{2}{*}{\multicolumn{3}{|c|}{ RCP 8.5}} \\
\hline \multicolumn{5}{|c|}{ RCP 4.5} & & & \\
\hline & Y1l Aralı̆ & AzYağAkd & YağAkd & YarıKurAkd & AzYağAkd & YağAkd & YarıKurAkd \\
\hline \multirow{4}{*}{$\mathrm{km}^{2}$} & 1970-2000 (RfD) & 152 & 11 & 3 & 152 & 11 & 3 \\
\hline & 2016-2040 & 2 & 164 & - & 1 & 165 & - \\
\hline & 2041-2070 & 6 & 159 & - & 2 & 164 & - \\
\hline & 2071-2099 & 17 & 149 & - & 73 & 93 & - \\
\hline \multirow{6}{*}{ 言 } & RfD-2040 & -99 & 1447 & - & -100 & 1459 & - \\
\hline & RfD-2070 & -96 & 1404 & - & -99 & 1446 & - \\
\hline & RfD-2099 & -89 & 1303 & - & -52 & 776 & - \\
\hline & $2040-2070$ & 253 & -3 & - & 239 & -1 & - \\
\hline & 2040-2099 & 834 & -9 & - & 12918 & -44 & - \\
\hline & $2070-2099$ & 165 & -7 & - & 3737 & -43 & - \\
\hline
\end{tabular}

\subsection{Karaçam-Kızılçam (Pinus nigra-Pinus brutia) Egemen Birliği:}

Kazdağı doğal orman alanı içerisinde yaklaşık $18 \mathrm{~km}^{2}$ alana sahip Karaçam-Kızılçam (ÇkÇz) egemen birliği içerisinde yer yer meşe'ler de yer alır (Hepbilgin 2019c). Karaçam-Kızılçam egemen birliği, kuzey yamaçta $240 \mathrm{~m}-741 \mathrm{~m}$ arasında; güney yamaçta ise $338 \mathrm{~m}$ ile $1131 \mathrm{~m}$ arasında yayılır (Hepbilgin \& Koç, 2019a). Erinç İklim Sınıflandırmasına göre, Karaçam-Kızılçam ormanlarında, 1970-2000 (RfD) döneminde $6.40 \mathrm{~km}^{2}$ 'lik alan nemli iklim koşulları altındayken, son periyotta (2071-2099) nemli iklim etkisini kaybederek birlik alanının neredeyse tamamında (\%95) yarı nemli iklim koşulları hakim duruma geçmiştir; ayrıca son periyotta çok küçük oranda da olsa yarı kurak iklim etkisinin geliştiği gözlenmektedir (Tablo 8). Kötümser senaryo (RCP 8.5) için de benzer fakat daha belirgin değişim durumu görülmektedir (Tablo 8). 
Tablo 8. Karaçam - Kızılçam (Pinus nigra - Pinus brutia) Egemen Birliğinde Alansal İklim Değisşimleri

\begin{tabular}{|c|c|c|c|c|c|c|c|c|c|}
\hline \multicolumn{3}{|c|}{ Pni-Pbru (ÇkÇz) } & \multicolumn{7}{|c|}{ ERINÇ } \\
\hline \multicolumn{6}{|c|}{ RCP 4.5} & \multicolumn{4}{|c|}{ RCP 8.5} \\
\hline & Y1l Aralığ 1 & $\begin{array}{l}\text { Çok } \\
\text { Nemli }\end{array}$ & Nemli & $\begin{array}{l}\text { Yar1 } \\
\text { Nemli }\end{array}$ & \begin{tabular}{|l|} 
Yar1 \\
Kurak
\end{tabular} & $\begin{array}{l}\text { Çok } \\
\text { Nemli }\end{array}$ & Nemli & $\begin{array}{l}\text { Yar1 } \\
\text { Nemli }\end{array}$ & $\begin{array}{l}\text { Yar1 } \\
\text { Kurak }\end{array}$ \\
\hline \multirow{4}{*}{$\mathrm{km}^{2}$} & 1970-2000 (RfD) & 0,05 & 6,40 & 11,30 & - & 0,05 & 6,45 & 11,30 & - \\
\hline & 2016-2040 & - & 3,15 & 14,66 & - & 0,05 & 5,80 & 11,80 & - \\
\hline & 2041-2070 & |- & 1,31 & 16,50 & - & - & 2,31 & 15,49 & - \\
\hline & 2071-2099 & - & 0,30 & 17,49 & 0,02 & - & 0,07 & 16,85 & 0,90 \\
\hline \multirow{3}{*}{ 芯 } & RfD-2040 & - & -51 & 30 & - & 2 & -10 & 4 & - \\
\hline & RfD-2070 & - & -80 & 46 & - & - & -64 & 37 & - \\
\hline & RfD-2099 & - & -95 & 55 & - & - & -99 & 49 & - \\
\hline \multirow{3}{*}{ 表 } & $2040-2070$ & - & -59 & 13 & - & - & -60 & 31 & - \\
\hline & $2040-2099$ & - & -90 & 19 & - & - & -99 & 43 & - \\
\hline & \begin{tabular}{|l|}
$2070-2099$ \\
\end{tabular} & - & -77 & 6 & - & - & -97 & 9 & - \\
\hline
\end{tabular}

Emberger İklim Sınıflandırmasına göre, ÇkÇz alanında, Referans Döneminde Az Yağışlı Akdeniz iklim hakimken, 2040 yılında sahanın iklim tipi değişmiş, Yağışlı Akdeniz iklimi hakim olmuştur. 2099 yılına doğru Az Yağlşlı Akdeniz iklimi yeniden egemen olmuştur (Tablo 9). Kötümser senaryoda da değişim deseni benzer fakat daha belirgindir (Tablo 9).

Tablo 9. Karaçam-Kızılçam (Pinus nigra-Pinus brutia) Egemen Birliğinde Alansal İklim Değişimleri Pni-Pbru (ÇkÇz) EMBERGER

\begin{tabular}{|c|c|c|c|c|c|c|c|}
\hline \multicolumn{5}{|c|}{ RCP 4.5} & \multicolumn{3}{|c|}{ RCP 8.5} \\
\hline & Yil Aralığ & AzYağ.Akd. & Yağ.Akd & Yar1Kur.Akd & AzYağ.Akd & Yağ.Akd. & Yar1KurAkd. \\
\hline \multirow{4}{*}{$\mathrm{km}^{2}$} & 1970-2000 RfD) & 16,90 & 0,06 & 0,80 & 16,90 & 0,06 & 0,80 \\
\hline & $2016-2040$ & 0,41 & 17,30 & - & 0,16 & 17,60 & - \\
\hline & $2041-2070$ & 1,48 & 16,32 & - & 0,42 & 17,30 & - \\
\hline & 2071-2099 & 4,14 & 13,60 & - & 12,40 & 5,37 & - \\
\hline \multirow{3}{*}{ 芯 } & RfD-2040 & -100 & 30793 & - & -99 & 31329 & - \\
\hline & RfD-2070 & -91 & 29043 & - & -98 & 30793 & - \\
\hline & RfD-2099 & -76 & 24186 & - & -27 & 9489 & - \\
\hline \multirow{3}{*}{ 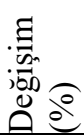 } & $2040-2070$ & 261 & -6 & - & 163 & -2 & - \\
\hline & 2040-2099 & 910 & -21 & - & 7650 & -69 & - \\
\hline & 2070-2099 & 180 & -17 & - & 2852 & -69 & - \\
\hline
\end{tabular}

\subsection{Karaçam-Göknar (Pinus nigra-Abies) Egemen Birliği:}

Kazdağı doğal orman alanı içerisinde yaklaşı $7 \mathrm{~km}^{2}$ 'lik alana sahip ÇkG birliğinde yer yer kayın da bulunur (Hepbilgin 2019c). Karaçam-Göknar ormanları, kuzey yamaçta 379m-1642m arasında; güney yamaçta ise, 668m-1624m arasında yayılır (Hepbilgin \& Koç, 2019a). Karaçam-Göknar ormanlarının büyük kesiminde Erinç iklim sınıflandırmasına göre, referans döneminde, çok nemli iklim koşulları hakimken, 2099 yılında nemli iklim hakim olmuştur (Tablo 10). Yarı nemli iklimin sahada alansal olarak az da olsa genişlemeye başladığı görülmektedir (Tablo 10). 
Tablo 10. Karaçam - Göknar (Pinus nigra - Abies) Egemen Birliğinde Alansal İklim Değişimleri

\begin{tabular}{|c|c|c|c|c|c|c|c|}
\hline \multicolumn{5}{|c|}{ Pni-Abi $(C ̧ k G)$} & \multirow{2}{*}{\multicolumn{3}{|c|}{ RCP 8.5}} \\
\hline \multicolumn{5}{|c|}{ RCP 4.5} & & & \\
\hline \multicolumn{3}{|c|}{ Yil Aralığ 1 Çok Nemli } & Nemli & Yar1 Nemli & Çok Nemli & Nemli & Yar1 Nemli \\
\hline \multirow{4}{*}{$\mathrm{km}^{2}$} & $1970-2000(\mathrm{RfD})$ & 5,11 & 1,30 & 0,05 & 5,11 & 1,30 & 0,05 \\
\hline & $2016-2040$ & 4,81 & 1,56 & 0,09 & 5,14 & 1,26 & 0,06 \\
\hline & $2041-2070$ & 3,25 & 2,94 & 0,27 & 4,60 & 1,73 & 0,14 \\
\hline & $2071-2099$ & 1,07 & 4,67 & 0,72 & 0,43 & 4,83 & 1,20 \\
\hline \multirow{6}{*}{ 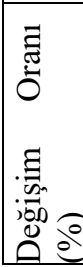 } & RfD-2040 & -6 & 20 & 80 & 1 & -3 & 20 \\
\hline & RfD-2070 & -36 & 126 & 416 & -10 & 33 & 180 \\
\hline & RfD-2099 & -79 & 259 & 1270 & -92 & 272 & 2300 \\
\hline & $2040-2070$ & -32 & 89 & 187 & -11 & 37 & 133 \\
\hline & $2040-2099$ & -78 & 200 & 660 & -92 & 283 & 1900 \\
\hline & $2070-2099$ & -67 & 59 & 165 & -91 & 179 & 757 \\
\hline
\end{tabular}

3.6 Karaçam-Maki (Pinus nigra-Maques) Egemen Birliği:

ÇkMa birliği, Kazdağı doğal orman alanı içerisinde yaklaşık 15 km² 'lik alana sahiptir; birliğin \%70'e yakını güney bakılı arazilerde bulunur (Hepbilgin, 2019c). Karaçam-Maki alanları Kazdağı'nın kuzey yamacında 750m-990m; güney yamacında 235m-1403m arasında yer alır (Hepbilgin \& Koç, 2019a). Erinç iklim sınıflandırmasında her iki senaryoya göre de, Karaçam-maki ormanlarında referans döneminde nemli iklim hakim iken üçüncü periyottan (2041-2070) itibaren yarl nemli iklimin hakim olduğu görülmektedir (Tablo 11). Yine, kötümser senaryoya (RCP 8.5) göre de, 2099 y1lına gelindiğinde sahada nemli iklim koşullarının neredeyse ortadan kalktığ ve yarı kurak ikliminin doğduğu görülmektedir (Tablo 11).

Tablo 11. Karaçam - Maki (Pinus nigra - Maquis) Egemen Birliğinde Alansal İklim Değişimleri

\begin{tabular}{|c|c|c|c|c|c|c|c|c|}
\hline \multicolumn{5}{|c|}{ Pni-Ma (ÇkMa) } & \multirow{2}{*}{\multicolumn{4}{|c|}{ RCP 8.5}} \\
\hline \multicolumn{5}{|c|}{ RCP 4.5} & & & & \\
\hline & Y1l Aralığ 1 & $\begin{array}{l}\text { Çok } \\
\text { Nemli }\end{array}$ & Nemli & Yar1 Nemli & Çok Nemli & Nemli & Yar1 Nemli & Yarı Kurak \\
\hline \multirow{4}{*}{$\mathrm{km}^{2}$} & $1970-2000(\mathrm{RfD})$ & 0,78 & 10,50 & 3,50 & 0,78 & 10,50 & 3,50 & - \\
\hline & 2016-2040 & 0,30 & 8,00 & 6,50 & 0,82 & 10,00 & 3,84 & - \\
\hline & $2041-2070$ & 0,12 & 5,60 & 9,00 & 0,20 & 6,43 & 8,08 & - \\
\hline & 2071-2099 & - & 4,15 & 10,60 & - & 1,50 & 13,00 & 0,31 \\
\hline \multirow{3}{*}{ 芯 } & RfD-2040 & -61 & -24 & 86 & 5 & -5 & 10 & - \\
\hline & RfD-2070 & -84 & -47 & 157 & -74 & -39 & 131 & - \\
\hline & RfD-2099 & - & -60 & 203 & - & -86 & 271 & - \\
\hline \multirow{3}{*}{ 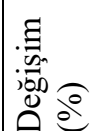 } & $2040-2070$ & -58 & -30 & 38 & -76 & -36 & 110 & - \\
\hline & $2040-2099$ & - & -48 & 63 & - & -85 & 239 & - \\
\hline & $2070-2099$ & - & -26 & 18 & - & -77 & 61 & - \\
\hline
\end{tabular}

Emberger İklim Sınıflandırması ve her iki senaryoya göre ise ÇkMa birliğinde tüm dönemlerdeki en büyük değişim 2000-2040 arasındadır. Karaçam-Maki birliğinde, Referans Dönemde Az Yağlşlı Akdeniz iklimi hakim iken, ilk periyot içerisinde (2016-2040) Yağışl Akdeniz iklim koşulları hakim olmuştur. Kötümser senaryodaki değişim deseni iyimser senaryoya benzer fakat daha belirgindir (Tablo 12). 
Tablo 12. Karaçam - Maki (Pinus nigra - Maquis) Egemen Birliğinde Alansal İklim Değişimleri

\begin{tabular}{|c|c|c|c|c|c|c|c|}
\hline \multicolumn{2}{|c|}{ Pni-Ma (ÇkMa) } & \multicolumn{3}{|c|}{ EMBERGER } & \\
\hline \multicolumn{5}{|c|}{ RCP 4.5} & \multicolumn{3}{|c|}{ RCP 8.5} \\
\hline & Y1l Aralığ 1 & AzYağAkd & YağAkd & YarıKurAkd & AzYağAkd & YağAkd & YarıKurAkd \\
\hline \multirow{4}{*}{$\mathrm{km}^{2}$} & 1970-2000 (RfD) & 13,50 & 0,83 & 0,39 & 13,50 & 0,83 & 0,39 \\
\hline & 2016-2040 & 0,35 & 14,30 & - & 0,32 & 14,40 & - \\
\hline & \begin{tabular}{|l|}
$2041-2070$ \\
\end{tabular} & 0,59 & 14,13 & - & 0,34 & 14,30 & - \\
\hline & \begin{tabular}{|l|}
$2071-2099$ \\
\end{tabular} & 0,96 & 13,70 & l- & 3,96 & 10,70 & - \\
\hline \multirow{3}{*}{ 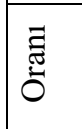 } & RfD-2040 & -97 & 1623 & - & -98 & 1635 & - \\
\hline & RfD-2070 & -96 & 1602 & - & -97 & 1623 & - \\
\hline & RfD-2099 & -93 & 1551 & - & -71 & 1189 & - \\
\hline \multirow{3}{*}{ 表 } & $2040-2070$ & 69 & -1 & - & 6 & -1 & - \\
\hline & 2040-2099 & 174 & -4 & - & 1138 & -26 & - \\
\hline & \begin{tabular}{|l|}
$2070-2099$ \\
\end{tabular} & 63 & -3 & - & 1065 & -25 & - \\
\hline
\end{tabular}

\section{Kızılçam (Pinus brutia) Birlikleri}

4.1 Kızllçam-Karaçam (Pinus brutia - Pinus nigra) Egemen Birliği:

ÇzÇk Birliği, Kazdağı doğal orman alanı içerisinde $21 \mathrm{~km}^{2}$ alana sahiptir. ÇzÇk birliği, içerisinde yer yer macar meşesi (Q. frainetto) toplulukları barındırır (Hepbilgin, 2019c). Kızılçam-Karaçam ormanları, Kazdağı'nın kuzey yamacında $211 \mathrm{~m}-232 \mathrm{~m}$ arasında; güney yamacında $256 \mathrm{~m}-958 \mathrm{~m}$ arasında yayılır (Hepbilgin \& Koç, 2019a). Kızılçam-Karaçam ormanlarının neredeyse tamamında tüm periyotlarda Yarı Nemli ikliminin hakim olduğu, 2071-2099 döneminde Yarı Kurak İklim koşullarının doğduğu söylenebilir (Tablo 13).

Tablo 13. Kızılçam - Karaçam (Pinus brutia - Pinus nigra) Egemen Birliğinde Alansal İklim Değişimleri

\begin{tabular}{|c|c|c|c|c|c|c|c|c|c|}
\hline \multirow{2}{*}{\multicolumn{6}{|c|}{ Pbru-Pni (ÇzÇk) }} & & & & \\
\hline RCP 4.5 & & & & & & \multicolumn{4}{|c|}{$\operatorname{RCP} 8.5$} \\
\hline & Yıl Aralı̆ & $\begin{array}{l}\text { Çok } \\
\text { Nemli }\end{array}$ & Nemli & $\begin{array}{l}\text { Yar1 } \\
\text { Nemli }\end{array}$ & $\begin{array}{l}\text { Yar1 } \\
\text { Kurak }\end{array}$ & $\begin{array}{l}\text { Çok } \\
\text { Nemli }\end{array}$ & Nemli & $\begin{array}{l}\text { Yar1 } \\
\text { Nemli }\end{array}$ & $\begin{array}{l}\text { Yar1 } \\
\text { Kurak }\end{array}$ \\
\hline \multirow[b]{4}{*}{$\mathrm{km}^{2}$} & 1970-2000 RfD) & - & 0,84 & 20,13 & - & - & 0,84 & 20,13 & - \\
\hline & 2016-2040 & - & 1,65 & 19,32 & - & - & 3,31 & 17,60 & - \\
\hline & 2041-2070 & - & 0,23 & 20,74 & - & - & 0,84 & 20,12 & - \\
\hline & 2071-2099 & - & 0,04 & 20,93 & 0,01 & $\begin{array}{lll}- & -\end{array}$ & - & 16,69 & 4,20 \\
\hline \multirow{3}{*}{ 苟 } & RfD-2040 & - & 97 & -4 & - & - & 294 & -13 & - \\
\hline & RfD-2070 & - & -73 & 3 & - & - & 0 & 0 & - \\
\hline & RfD-2099 & - & -96 & 4 & - & - & - & -17 & - \\
\hline \multirow{3}{*}{ 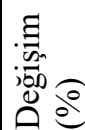 } & 2040-2070 & - & -86 & 7 & - & - & -75 & 14 & - \\
\hline & 2040-2099 & - & -98 & 8 & - & - & - & -5 & - \\
\hline & $2070-2099$ & - & -84 & 1 & - & - & - & -17 & - \\
\hline
\end{tabular}

Emberger iklim sınıflandırmasında sahada Referans dönemde $A z$ Yağışlı Akdeniz iklimi hakimdir. Ilk periyotta (2016-2040) Az Yağışlı Akdeniz iklim etkisi neredeyse tamamen ortadan kalkarak Yağışlı Akdeniz İklim koşulları hakim duruma geçmiştir. 2040 yılından sonra Yağışlı Akdeniz iklimi KızılçamKaraçam ormanlarında egemenliğini sürdürse de $\% 6$ ve $\% 28$ oranlarında alan ve etki kaybetmiştir (Tablo 14). 
Tablo 14. Kızılçam - Karaçam (Pinus brutia - Pinus nigra) Egemen Birliğinde Alansal İklim Değişimleri

\begin{tabular}{|c|c|c|c|c|c|c|c|}
\hline \multirow{2}{*}{\multicolumn{5}{|c|}{$\begin{array}{c}\text { EMBERGER } \\
\text { RCP } 4.5\end{array}$}} & \multirow{2}{*}{\multicolumn{3}{|c|}{ RCP 8.5}} \\
\hline & & & & & & & \\
\hline & Yil Aralığ & AzYağAkd & YağAkd & YarıKurAkd & AzYağAkd & YağAkd & YarıKurAkd \\
\hline \multirow{4}{*}{$\mathrm{km}^{2}$} & 1970-2000 RfD) & 18,9 & - & 2,02 & 18,9 & - & 2,02 \\
\hline & $2016-2040$ & 2 & 19 & - & 1 & 20 & - \\
\hline & $2041-2070$ & 3 & 18 & - & 1,49 & 19,4 & - \\
\hline & 2071-2099 & 7 & 14 & - & 18 & 3 & - \\
\hline \multirow{3}{*}{ 芯 } & RfD-2040 & -91 & - & - & -95 & - & - \\
\hline & RfD-2070 & -85 & - & - & -92 & - & - \\
\hline & RfD-2099 & -62 & - & - & -4 & - & - \\
\hline \multirow{3}{*}{ 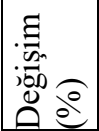 } & $2040-2070$ & 80 & -6 & - & 48 & -3 & - \\
\hline & 2040-2099 & 343 & -28 & - & 1702 & -86 & - \\
\hline & 2070-2099 & 147 & -24 & - & 1121 & -86 & - \\
\hline
\end{tabular}

4.2 Kızılçam-Meşe (Pinus brutia-Quercus) Egemen Birliği:

Kızılçam-Meşe (ÇzM) Birlik alanı Kazdağı'nda yaklaşık $29 \mathrm{~km}^{2}$ alana sahiptir. Kızılçam-Meşe ormanlarında meşe türü olarak çoğunlukla macar meşesi (Q.frainetto) görülmektedir (Hepbilgin, 2019c). Kızılçam-Meşe ormanları Kazdağı kuzey yamacında 159m - 776m arasında iken, güney yamacında $66 \mathrm{~m}$ - 1064m arasında yayılır (Tablo 15). Kızılçam-Meşe ormanlarında referans dönem de dahil olmak üzere tüm dönemlerde yarı nemli iklim koşulları egemen iken, dönemler sürecinde çok nemli ve nemli iklim alanlarının her iki senaryoda da tamamen ortadan kalktığı görülmektedir. Ayrıca, son iki projeksiyon döneminde yarı kurak iklim koşullarının gelişmekte olduğu söylenebilir (Tablo 15).

Tablo 15. Kızılçam - Meşe (Pinus brutia - Quercus) Egemen Birliğinde Alansal İklim Değişimleri

\begin{tabular}{|c|c|c|c|c|c|c|c|c|c|}
\hline \multicolumn{6}{|c|}{ Pbru-Qu (ÇzM) } & \multirow{2}{*}{\multicolumn{4}{|c|}{ RCP 8.5}} \\
\hline \multicolumn{6}{|c|}{ RCP 4.5} & & & & \\
\hline \multirow{5}{*}{$\mathrm{km}^{2}$} & Y1l Aralığ & \begin{tabular}{|l} 
Çok \\
Nemli
\end{tabular} & Nemli & $\begin{array}{l}\text { Yar1 } \\
\text { Nemli }\end{array}$ & $\begin{array}{l}\text { Yar1 } \\
\text { Kurak }\end{array}$ & $\begin{array}{l}\text { Çok } \\
\text { Nemli }\end{array}$ & Nemli & Yarı Nemli & \begin{tabular}{|l} 
Yar1 \\
Kurak
\end{tabular} \\
\hline & $1970-2000$ (RfD) & 0,002 & 9,92 & 18,70 & - & 0,00 & 9,92 & 18,70 & - \\
\hline & $2016-2040$ & - & 3,21 & 25,46 & 0,00 & 0,00 & 9,09 & 19,50 & - \\
\hline & $2041-2070$ & - & 0,74 & 27,43 & 0,51 & - & 1,63 & 27,03 & 0,01 \\
\hline & 2071-2099 & - & 0,16 & 24,55 & 3,98 & - & 0,00 & 20,82 & 7,84 \\
\hline \multirow{6}{*}{ 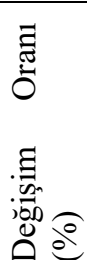 } & RfD-2040 & - & -68 & 36 & - & 300 & -8 & 4 & - \\
\hline & RfD-2070 & - & -93 & 47 & - & -100 & -84 & 45 & - \\
\hline & RfD-2099 & - & -98 & 31 & - & -100 & -100 & 11 & - \\
\hline & $2040-2070$ & - & -77 & 8 & 12726 & -100 & -82 & 39 & - \\
\hline & $2040-2099$ & - & -95 & -4 & 99314 & -100 & -100 & 7 & - \\
\hline & $2070-2099$ & - & -79 & -11 & 675 & - & -100 & -23 & 78300 \\
\hline
\end{tabular}

Emberger İklim sınıflandırmasında ise, ÇzM birliğinde, Referans Dönemde Az Yağışlı Akdeniz iklimi hakim iken, ilk iki projeksiyon dönemi (2016-2040 ve 2041-2070) içerisinde sahada Yağışl Akdeniz iklimi hakim olmuştur (Tablo 16). Kızılçam-Meşe ormanlarında Yağışlı Akdeniz iklimi 2070 yılından itibaren \%32 oranında alansal olarak etkisini kaybederken Az Yağışlı Akdeniz iklimi \%67 oranında etki alanını genişletmiştir (Tablo 16). 
Tablo 16. Kızılçam - Meşe (Pinus brutia - Quercus) Egemen Birliğinde Alansal İklim Değişimleri

\begin{tabular}{|c|c|c|c|c|c|c|c|}
\hline \multicolumn{5}{|c|}{ Pbru-Qu (ÇzM) } & \\
\hline \multicolumn{5}{|c|}{ RCP 4.5} & \multicolumn{2}{|r|}{ RCP 8.5} & \\
\hline & Y1l Aralı̆̆ & AzYağAkd & YağAkd & YarıKurAkd & AzYağAkd & YağAkd & YarıKurAkd \\
\hline \multirow{4}{*}{$\mathrm{km}^{2}$} & 1970-2000 (RfD) & 22,30 & 0,00 & 6,36 & 22,30 & 0,00 & 6,36 \\
\hline & 2016-2040 & 3,92 & 24,50 & - & 1,20 & 27,40 & - \\
\hline & $2041-2070$ & 9,26 & 19,40 & - & 3,21 & 25,40 & - \\
\hline & 2071-2099 & 15,50 & 13,12 & - & 22,70 & 5,70 & 0,24 \\
\hline \multirow{3}{*}{ 苟 } & RfD-2040 & -82 & 2578847 & - & -95 & 2884111 & - \\
\hline & RfD-2070 & -58 & 2042005 & - & -86 & 2673584 & - \\
\hline & RfD-2099 & -31 & 1380953 & - & 2 & 599900 & -96 \\
\hline \multirow{3}{*}{ 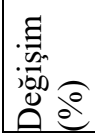 } & $2040-2070$ & 136 & -21 & - & 168 & -7 & - \\
\hline & $2040-2099$ & 295 & -46 & - & 1792 & -79 & - \\
\hline & 2070-2099 & 67 & -32 & - & 607 & -78 & - \\
\hline
\end{tabular}

4.3 Klzılçam-Diğer Yapraklılar (Pinus brutia - Other Leafed Trees) Egemen Birliği:

Kızılçam - Diğer Yapraklılar (ÇzDy) egemen birliği, Kazdağı doğal orman alanı içerisinde 9 km²' lik bir alan teşkil etmektedir (Tablo 17). ÇzDy egemen birliği, Kazdağı kuzey yamacında 219m - 616m arasında, güney yamacında ise 138m-889m arasında yayılır (Hepbilgin \& Koç, 2019a). Kızılçam - Diğer Yapraklılar ormanlarında her iki senaryoya göre de yarl nemli iklim egemen ve küçük bir alanda nemli $i k l i m$ hakimdir. Son projeksiyon döneminde yarl nemli iklim iyimser senayoya göre \%13 oranında, kötümser senayoya göre ise $\sim \% 30-40$ oranında alan kaybederek yarı kurak iklim alanı doğmuştur (Tablo 17).

Tablo 17. Kızılçam - Diğer Yapraklılar (Pinus brutia - Other Leafed-Trees) Egemen Birliğinde Alansal İklim Değişimleri

\begin{tabular}{|c|c|c|c|c|c|c|c|}
\hline \multicolumn{5}{|c|}{ Pbru-OtLe (ÇzDy) } & \multirow{2}{*}{\multicolumn{3}{|c|}{ RCP 8.5}} \\
\hline \multicolumn{5}{|c|}{ RCP 4.5} & & & \\
\hline \multicolumn{2}{|r|}{ Yil Aralı̆ } & Nemli & Yar1 Nemli & Yarı Kurak & Nemli & Yar1 Nemli & Yar1 Kurak \\
\hline \multirow{4}{*}{$\mathrm{km}^{2}$} & $1970-2000(\mathrm{RfD})$ & 1.60 & 7.11 & - & 1.60 & 7.10 & - \\
\hline & $2016-2040$ & 0.61 & 8.06 & 0.00 & 1.40 & 7.31 & - \\
\hline & 2041-2070 & 0.04 & 8.17 & 0.46 & 0.26 & 8.41 & - \\
\hline & 2071-2099 & - & 7.10 & 1.58 & - & 5.20 & 3.50 \\
\hline \multirow{3}{*}{ 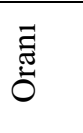 } & RfD-2040 & -62 & 13 & - & -13 & 3 & - \\
\hline & RfD-2070 & -98 & 15 & - & -84 & 18 & - \\
\hline & RfD-2099 & - & -0.13 & - & - & -27 & - \\
\hline \multirow{3}{*}{ 声 } & $2040-2070$ & -94 & 1 & - & -81 & 15 & - \\
\hline & 2040-2099 & - & -12 & - & - & -29 & - \\
\hline & 2070-2099 & - & -13 & - & - & -38 & - \\
\hline
\end{tabular}

Emberger İklim sınıflandırmasına göre, her iki senaryo için de Kızılçam-Diğer Yapraklılar ormanlarında Referans Dönemde Az Yağışlı Akdeniz iklimi hakimdir. İlk projeksiyon döneminde (2016-2040) Yă̆lşlı Akdeniz iklimi egemen olmuştur (Tablo 18). 2040 yılından sonra Az Yağışlı Akdeniz iklim etkisi genişlemiştir (Tablo 18). Son periyotta (2071-2099) her iki senaryoya göre de Az Yağışlı Akdeniz iklimi hakimiyet kazanırken, Yağışı Akdeniz ikliminin alansal etkisi daralmıştır (Tablo 18). 
Tablo 18. Kızılçam - Diğer Yapraklılar (Pinus brutia - Other Leafed-Trees) Egemen Birliğinde Alansal İklim Değişimleri

\begin{tabular}{|c|c|c|c|c|c|c|c|}
\hline \multicolumn{5}{|c|}{ Pbru-OtLe (ÇzDy) } & \multirow{2}{*}{\multicolumn{3}{|c|}{ RCP 8.5}} \\
\hline \multicolumn{5}{|c|}{ RCP 4.5} & & & \\
\hline & Y1l Aralığg & AzYağAkd & YağAkd & YarıKurAkd & AzYağAkd & YağAkd & YarıKurAkd \\
\hline \multirow{4}{*}{$\mathrm{km}^{2}$} & $1970-2000(\mathrm{RfD})$ & 5,30 & - & 3,37 & 5,30 & - & 3,37 \\
\hline & $2016-2040$ & 2,47 & 6,20 & - & 1,09 & 7,57 & - \\
\hline & $2041-2070$ & 4,17 & 4,49 & - & 2,18 & 6,50 & - \\
\hline & 2071-2099 & 5,68 & 2,98 & - & 7,56 & 0,97 & 0,13 \\
\hline \multirow{3}{*}{ 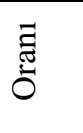 } & RfD-2040 & -53 & - & - & -79 & - & - \\
\hline & RfD-2070 & -21 & - & - & -59 & - & - \\
\hline & \begin{tabular}{|l|} 
RfD-2099 \\
\end{tabular} & 7 & - & - & 43 & - & -96 \\
\hline \multirow{3}{*}{ 声 } & $2040-2070$ & 69 & -28 & - & 100 & -14 & - \\
\hline & 2040-2099 & 130 & -52 & - & 594 & -87 & - \\
\hline & 2070-2099 & 36 & -34 & - & 247 & -85 & - \\
\hline
\end{tabular}

\section{Saf Ăgaç Toplulukları}

\subsection{Meşe (Quercus) Alanı:}

Kazdağı'nda 37 km² alan kaplayan meşe'nin 1970-2000 Referans Dönemi'nde 23 km², sinde yarl nemli iklim; $13 \mathrm{~km}^{2}$ ' sinde de nemli iklim hakimdir (Tablo 19). Kazdağ 1 kuzey yamacında meşe, 90m - 1212m aralığında iken; güney yamacında, 78m - 1367m aralığında yayılmaktadır (Hepbilgin \& Koç, 2019a). Erinç iklim sınıflandırmasına göre meşe ormanları, Referans Döneminde nemli iklim ve yarı nemli iklim koşulları altında iken, her iki senaryoya göre ilk projeksiyon dönemi (2016-2040) içerisinde sahada yart nemli iklim, dönemler sonuna kadar hakimiyetini sürdürmektedir (Tablo 19). Son projeksiyon döneminde (2071-2099) yarı kurak iklim alanı dikkate değer bir genişleme kaydetmiştir. Kötümser senaryoda (RCP 8.5) değişim deseni benzer olmakla birlikte daha belirgindir (Tablo 19).

Tablo 19. Meşe (Quercus) Ormanlarındaki Alansal İklim Değişimleri

\begin{tabular}{|c|c|c|c|c|c|c|c|c|c|}
\hline \multicolumn{2}{|c|}{$Q u(M)$} & \multicolumn{8}{|c|}{ ERINCC } \\
\hline \multicolumn{6}{|c|}{ RCP 4.5} & \multicolumn{4}{|c|}{ RCP 8.5} \\
\hline & Y1l Aralı̆̆g & $\begin{array}{l}\text { Çok } \\
\text { Nemli }\end{array}$ & Nemli & $\begin{array}{l}\text { Yar1 } \\
\text { Nemli }\end{array}$ & $\begin{array}{l}\text { Yar1 } \\
\text { Kurak }\end{array}$ & $\begin{array}{l}\text { Çok } \\
\text { Nemli }\end{array}$ & Nemli & $\begin{array}{l}\text { Yar1 } \\
\text { Nemli }\end{array}$ & $\begin{array}{l}\text { Yar1 } \\
\text { Kurak }\end{array}$ \\
\hline \multirow{4}{*}{$\mathrm{km}^{2}$} & $1970-2000$ (RfD) & 1.10 & 13.04 & 23.03 & - & 1.10 & 13.00 & 23.03 & - \\
\hline & 2016-2040 & 0.10 & 10.32 & 26.74 & 0.01 & 1.25 & 12.30 & 23.60 & - \\
\hline & $2041-2070$ & 0.03 & 7.60 & 28.82 & 0.75 & 0.01 & 8.82 & 28.25 & 0.03 \\
\hline & 2071-2099 & - & 5.09 & 29.58 & 2.52 & - & 2.08 & 26.33 & 8.80 \\
\hline \multirow{3}{*}{ 芯 } & RfD-2040 & -91 & -21 & 16 & - & 14 & -5 & 2 & - \\
\hline & RfD-2070 & -97 & -42 & 25 & - & -99 & -32 & 23 & - \\
\hline & RfD-2099 & I- & -61 & 28 & - & - & -84 & 14 & - \\
\hline \multirow{3}{*}{ 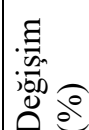 } & $2040-2070$ & -71 & -26 & 8 & 7358 & -99 & -28 & 20 & - \\
\hline & 2040-2099 & - & -51 & 11 & 25120 & - & -83 & 12 & - \\
\hline & $2070-2099$ & - & -33 & 3 & 238 & - & -76 & -7 & 29233 \\
\hline
\end{tabular}

Emberger İklim Sınıflandırmasına göre Kazdağı'ndaki tüm meşe alanının büyük bölümü Referans Döneminde Az Yağışlı Akdeniz iklimi etkisi altındadır (Tablo 20). 2040 ve 2070 yıllarına gelindiğinde sahada Yağışlı Akdeniz iklimi egemen olmuştur (Tablo 20). 2099 yılına gelindiğinde meşe alanında, iyimser senaryoya göre Yă̆ışlı Akdeniz iklimi, kötümser senaryoya göre Az Yağlşlı Akdeniz iklimi egemen durumdadir (Tablo 20). 
Table 20. Meşe (Quercus) Ormanlarındaki Alansal İklim Değişimleri

\begin{tabular}{|c|c|c|c|c|c|c|c|}
\hline \multirow[t]{3}{*}{$Q u(M)$} & \multirow{2}{*}{\multicolumn{4}{|c|}{$\begin{array}{c}\text { EMBERGER } \\
\text { RCP } 45\end{array}$}} & \multirow{2}{*}{\multicolumn{3}{|c|}{ RCP 85}} \\
\hline & & RCP 4.5 & & & & & \\
\hline & Y1l Aralığ & AzYağAkd & YağAkd & YarıKurAkd & AzYağAkd & YağAkd & YarıKurAkd \\
\hline \multirow{4}{*}{$\mathrm{km}^{2}$} & $1970-2000(\mathrm{RfD})$ & 26.10 & 1.28 & 9.78 & 26.10 & 1.28 & 9.80 \\
\hline & $2016-2040$ & 7.50 & 29.60 & - & 4.49 & 32.60 & - \\
\hline & $2041-2070$ & 11.50 & 25.68 & - & 7.01 & 30.10 & - \\
\hline & \begin{tabular}{|l|}
$2071-2099$ \\
\end{tabular} & 14.30 & 22.70 & 0.03 & 23.80 & 13.20 & 0.10 \\
\hline \multirow{6}{*}{ 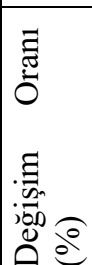 } & RfD-2040 & -71 & 2213 & - & -83 & 2447 & - \\
\hline & RfD-2070 & -56 & 1906 & - & -73 & 2252 & - \\
\hline & \begin{tabular}{|l|} 
RfD-2099 \\
\end{tabular} & -45 & 1673 & -100 & -9 & 931 & -99 \\
\hline & $2040-2070$ & 53 & -13 & - & 56 & -8 & - \\
\hline & \begin{tabular}{|l|}
$2040-2099$ \\
\end{tabular} & 91 & -23 & - & 430 & -60 & - \\
\hline & \begin{tabular}{|l}
$2070-2099$ \\
\end{tabular} & 24 & -12 & - & 240 & -56 & - \\
\hline
\end{tabular}

\subsection{Karaçam (Pinus nigra) Alanlart:}

Karaçam (Çk), Kazdağı doğal orman alanının \%34’ünü kapsar (Hepbilgin, 2019c). Kazdağı kuzey yamacında Karaçam ormanları 216m-1708m arasında; güney yamacında ise $273 \mathrm{~m}-1735 \mathrm{~m}$ arasında yayılmaktadır (Tablo 21). Karaçam ormanları Erinç İklim Sınıflandırmasına göre nemli, yarı nemli ve çok nemli iklim etkisi altındadır (Tablo 21). 2000-2099 sürecinde, iyimser senaryoya göre çok nemli iklim \%85; nemli iklim \%33 oranında alansal etkisini kaybetmiş, yarı nemli iklim \%139 oranında genişlemiştir. Kötümser senaryo için de değişim deseni benzer fakat belirgindir, ayrıca son periyotta karaçam ormanlarında $5.30 \mathrm{~km}^{2}$ ' lik alanın yarı kurak iklim etkisine gireceği görülmektedir (Tablo 21).

Tablo 21. Karaçam (Pinus nigra) Ormanlarındaki Alansal İklim Değişimleri

\begin{tabular}{|c|c|c|c|c|c|c|c|c|c|}
\hline \multicolumn{2}{|c|}{$P n i(C ̧ k)$} & \multicolumn{4}{|c|}{ ERINCC } & \multirow{2}{*}{\multicolumn{4}{|c|}{ RCP 8 5}} \\
\hline \multicolumn{6}{|c|}{ RCP 4.5} & & & & \\
\hline & Yil Aralı̆ & \begin{tabular}{|l|} 
Çok \\
Nemli \\
\end{tabular} & Nemli & \begin{tabular}{|l|} 
Yar1 \\
Nemli \\
\end{tabular} & \begin{tabular}{|l|} 
Yar1 \\
Kurak
\end{tabular} & \begin{tabular}{|l|} 
Çok \\
Nemli \\
\end{tabular} & Nemli & \begin{tabular}{|l|} 
Yar1 \\
Nemli
\end{tabular} & \begin{tabular}{|l|} 
Yar1 \\
Kurak \\
\end{tabular} \\
\hline \multirow{4}{*}{$\mathrm{km}^{2}$} & 1970-2000 (RfD) & 98.08 & 199.00 & 107.91 & - & 98.08 & 198.80 & 107.90 & - \\
\hline & 2016-2040 & 71.70 & 165.09 & 168.06 & - & 100.50 & 188.30 & 115.90 & - \\
\hline & 2041-2070 & 33.39 & 149.27 & 222.19 & - & 60.30 & 145.00 & 199.40 & - \\
\hline & 2071-2099 & 14.30 & 132.38 & 258.00 & 0.06 & 7.34 & 104.20 & 287.93 & 5.30 \\
\hline \multirow{3}{*}{ 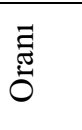 } & RfD-2040 & -27 & -17 & 56 & - & 2 & -5 & 7 & - \\
\hline & RfD-2070 & -66 & -25 & 106 & - & -39 & -27 & 85 & - \\
\hline & RfD-2099 & -85 & -33 & 139 & - & -93 & -48 & 167 & - \\
\hline \multirow{3}{*}{ 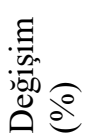 } & $2040-2070$ & -53 & -10 & 32 & - & -40 & -23 & 72 & - \\
\hline & 2040-2099 & -80 & -20 & 54 & - & -93 & -45 & 148 & - \\
\hline & 2070-2099 & -57 & -11 & 16 & - & -88 & -28 & 44 & - \\
\hline
\end{tabular}

Emberger iklim sınıflandırmasına göre, karaçam ormanlarının referans döneminde $292 \mathrm{~km}^{2}$ 'si $A z$ Yağışl $l$ Akdeniz iklimi etkisi altında iken, 102 km² si Yağışl Akdeniz iklimi etkisi altındadır (Tablo 22). 2040 yılına gelindiğinde karaçam orman alanının neredeyse tamamının Yağışl Akdeniz iklim etkisi altına girdiği görülmektedir (Tablo 22). 2016-2040 döneminden itibaren karaçam ormanlarında Yağgş̧l Akdeniz ikliminin etkisi küçük oranlarda azalsa da sahada egemenliğinin sürdüğü görülmektedir (Tablo 22). Kötümser senaryoya göre de değişim deseni benzer olmakla birlikte daha belirgindir (Tablo 22). 
Tablo 22. Karaçam (Pinus nigra) Ormanlarındaki Alansal İklim Değişimimleri

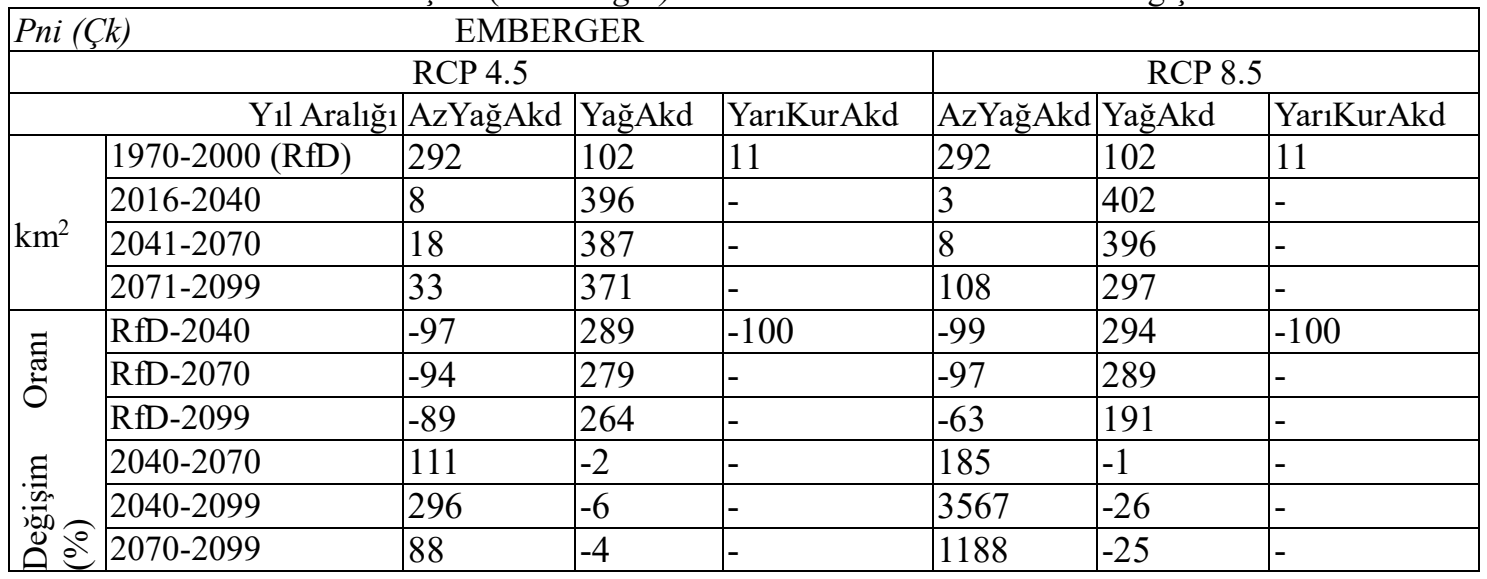

\subsection{Kızılçam (Pinus brutia) Alanları:}

Kızılçam, Kazdağı doğal orman alanı içerisinde 296 km² alana sahiptir. Kızılçam ormanları, Kazdağı kuzey yamacında 70m - $757 \mathrm{~m}$ arasında; güney yamacında ise, 0m-1175m arasında yayılmaktadır. Kızılçam ormanlarının neredeyse tamamında tüm dönemlerde Erinç iklim sınıflandırmasına göre, yarı nemli iklim hakimdir (Tablo 23). Referans Döneminde Kızılçam orman alanının $25 \mathrm{~km}^{2}$ sinde, nemli iklim görülmekle birlikte sonraki dönemlerde bu iklim tipi sahada etkisini kaybetmektedir (Tablo 23). 20712099 döneminde Kızılçam ormanlarında her iki senaryoya göre de yarı nemli iklim egemen ve yarı kurak iklim etkilidir. Kötümser senaryoda ise değişim benzer olmakla birlikte daha belirgindir (Tablo 23)

Tablo 23. Kızılçam (Pinus brutia) Ormanlarındaki Alansal İklim Değişimleri

\begin{tabular}{|c|c|c|c|c|c|c|c|c|c|}
\hline \multicolumn{2}{|c|}{ Pbru (Çz) } & \multicolumn{4}{|c|}{ ERİNÇ } & \multicolumn{4}{|c|}{ 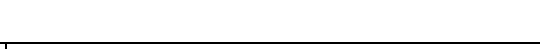 } \\
\hline \multicolumn{6}{|c|}{ RCP 4.5} & \multicolumn{4}{|c|}{ RCP 8.5} \\
\hline & Yil Aralı̆ & $\begin{array}{l}\text { Çok } \\
\text { Nemli }\end{array}$ & Nemli & $\begin{array}{l}\text { Yar1 } \\
\text { Nemli }\end{array}$ & $\begin{array}{l}\text { Yar1 } \\
\text { Kurak }\end{array}$ & Çok Nemli & Nemli & $\begin{array}{l}\text { Yar1 } \\
\text { Nemli }\end{array}$ & $\begin{array}{l}\text { Yar1 } \\
\text { Kurak }\end{array}$ \\
\hline \multirow{4}{*}{$\mathrm{km}^{2}$} & $1970-2000$ (RfD) & 0,07 & 25 & 270 & - & 0,07 & 25 & 270 & - \\
\hline & 2016-2040 & 0,01 & 6 & 287 & 3 & 0,08 & 22 & 274 & \\
\hline & 2041-2070 & - & 1 & 268 & 27 & 0,00 & 3 & 282 & 11 \\
\hline & 2071-2099 & - & 0,22 & 222 & 73 & - & 0,12 & 155 & 141 \\
\hline \multirow{3}{*}{ 胥 } & RfD-2040 & -84 & -76 & 6 & - & - & -15 & 1 & - \\
\hline & RfD-2070 & |- & -96 & -1 & - & -94 & -89 & 4 & - \\
\hline & RfD-2099 & |- & -99 & -18 & - & - & -100 & -43 & - \\
\hline \multirow{3}{*}{ 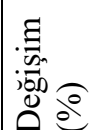 } & $2040-2070$ & - & -85 & -7 & 804 & -95 & -87 & 3 & - \\
\hline & 2040-2099 & - & -96 & -23 & 2346 & - & -99 & -44 & - \\
\hline & $2070-2099$ & - & -75 & -17 & 171 & - & -96 & -45 & 1177 \\
\hline
\end{tabular}

Emberger İklim sınıflandırmasına göre, Kazdağı'nda kızılçam ormanlarının büyük bir bölümü Referans Döneminde (RfD) Az Yă̆lşlı Akdeniz iklimi ve Yarı kurak Akdeniz iklimi etkisi altındadır (Tablo 24). 2040 yılına gelindiğinde ise Yağışlı Akdeniz ikliminin egemen olduğu görülmektedir. 2099 yılına doğru kızılçam ormanlarında yine Az Yağışlı Akdeniz iklim koşulları egemen olmuştur (Tablo 24). Kötümser senaryo için de durum benzer ve daha belirgindir, 2071-2099 döneminde sahada yarı kurak Akdeniz iklim koşullarının yeniden gelişmekte olduğu söylenebilir (Tablo 24). 
Tablo 24. Kızılçam (Pinus brutia) Ormanlarında Alansal İklim Değişimleri

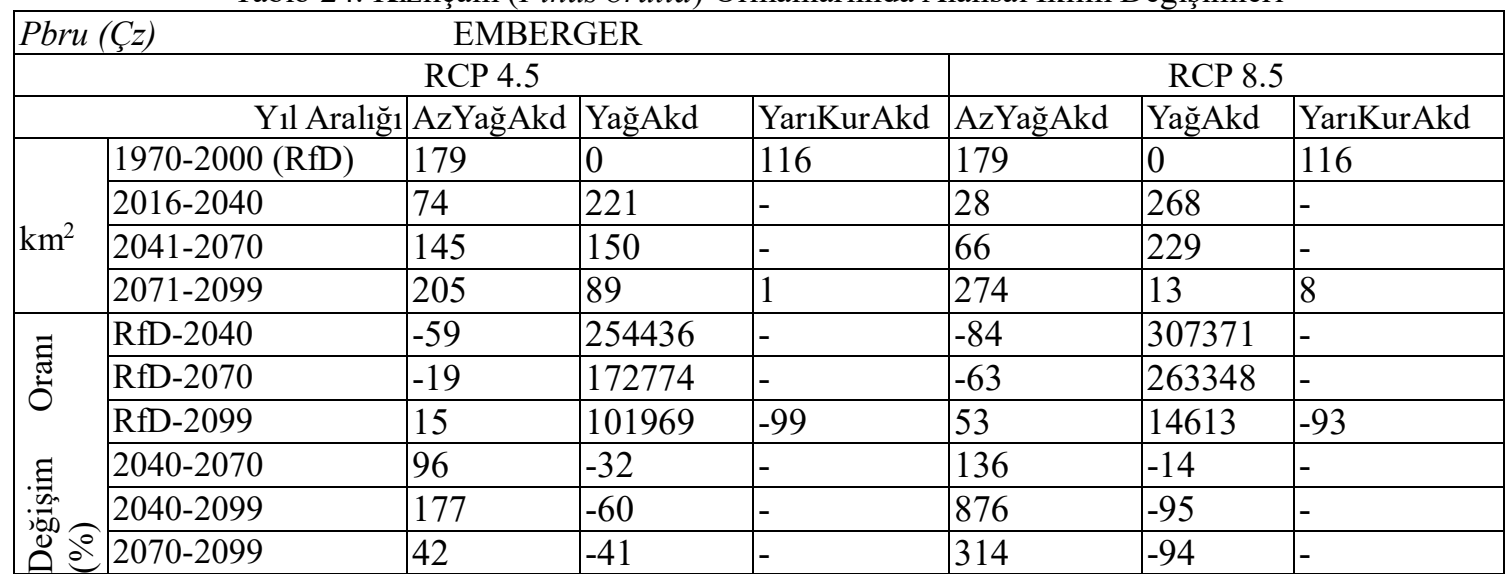

\section{Meșe (Quercus) Birlikleri}

6.1 Meşe-Karaçam (Quercus - Pinus nigra) Egemen Birliği:

$68 \mathrm{~km}^{2}$ alana sahip olan Meşe-Karaçam (MÇk) Birliği, Kazdağı'nın kuzey yamacında, 298m - 1249m; güney yamacında, 392m - 1284m arasında yayılır (Hepbilgin \& Koç, 2019a). Meşe-Karaçam ormanlarında Erinç iklim sınıflandırmasına göre, yakın oranlarda nemli ve yarı nemli iklim egemendir. Bununla birlikte 2000-2099 sürecinde nemli iklimin kademeli olarak etkisini kaybettiği görülmektedir (Tablo 25). Bu süreçte nemli iklim alanı sırasıyla $\% 35, \% 61$ ve $\% 41$ oranlarında azalırken, yarı nemli iklim alanı aynı dönemler için sırasıyla $\% 21, \% 37$ ve \%13 oranlarında alan kazanmıştır (Tablo 25). Kötümser senaryoda da durumun benzer olduğu, bununla birlikte daha yüksek değişim oranları elde edildiği görülmektedir (Tablo 25).

Tablo 25. Meşe - Karaçam (Quercus - Pinus nigra) Egemen Birliğinde Alansal İklim Değişimleri

\begin{tabular}{|c|c|c|c|c|c|c|c|}
\hline \multirow{2}{*}{\multicolumn{5}{|c|}{ QuPni (MÇk) }} & \multirow{2}{*}{\multicolumn{3}{|c|}{ RCP 8.5}} \\
\hline & & & & RCP 4.5 & & & \\
\hline & Yil Aral & Çok Nemli & Nemli & Yar1 Nemli & Çok Nemli & Nemli & Yarı Nemli \\
\hline \multirow{4}{*}{$\mathrm{km}^{2}$} & $1970-2000$ (RfD) & 1,63 & 33,5 & 33 & 2 & 34 & 33 \\
\hline & $2016-2040$ & 0,19 & 26 & 42 & 2 & 31 & 35 \\
\hline & $2041-2070$ & 0,03 & 17 & 51 & 0 & 21 & 47 \\
\hline & \begin{tabular}{|l|}
$2071-2099$ \\
\end{tabular} & - & 10 & 58 & - & 3 & 65 \\
\hline \multirow{6}{*}{ 节 } & RfD-2040 & -88 & -22 & 29 & 14 & -6 & 6 \\
\hline & RfD-2070 & -98 & -49 & 56 & -96 & -39 & 44 \\
\hline & RfD-2099 & - & -70 & 77 & - & -92 & 98 \\
\hline & $2040-2070$ & -87 & -35 & 21 & -96 & -34 & 36 \\
\hline & \begin{tabular}{|l|}
$2040-2099$ \\
\end{tabular} & - & -61 & 37 & - & -91 & 88 \\
\hline & $2070-2099$ & - & -41 & 13 & - & -86 & 38 \\
\hline
\end{tabular}

Emberger iklim sınıflandırmasına göre ise Meşe-Karaçam ormanlarında Referans Dönemde Az Yağış̧l Akdeniz iklimi hakimdir. Fakat ilk projeksiyon döneminde (2016-2040), Yağışlı Akdeniz iklimi egemen duruma geçmiş, 2099 yllına kadar \%6 ve \%4 oranlarında alan kaybetmekle birlikte hakimiyetini sürdürmüş̧ür (Tablo 26). Kötümser senaryoda özellikle 2071-2099 arasında Yağı̆şl Akdeniz iklimi \%47 oranında alan kaybederek Az Yağışlı Akdeniz iklimi $\left(32 \mathrm{~km}^{2}\right)$ yeniden etkisini genişletmeye başlamıştır (Tablo 26). 
Table 26. Meşe - Karaçam (Quercus - Pinus nigra) Egemen Birliğinde Alansal İklim Değişimleri

\begin{tabular}{|c|c|c|c|c|c|c|c|}
\hline \multicolumn{5}{|c|}{ QuPni (MÇk) } & \multirow{2}{*}{\multicolumn{3}{|c|}{ RCP 8.5}} \\
\hline \multicolumn{5}{|c|}{ RCP 4.5} & & & \\
\hline & Y1l Aralı̆̆ & AzYağAkd & YağAkd & YarıKurAkd & AzYağAkd & YağAkd & YarıKurAkd \\
\hline \multirow{4}{*}{$\mathrm{km}^{2}$} & $1970-2000$ (RfD) & 66 & 2 & 0,27 & 66 & 2 & 0,20 \\
\hline & $2016-2040$ & 0,12 & 68 & - & 0 & 68 & - \\
\hline & $2041-2070$ & 1 & 67 & - & 0 & 68 & - \\
\hline & 2071-2099 & 4 & 64 & - & 32 & 36 & - \\
\hline \multirow{6}{*}{ 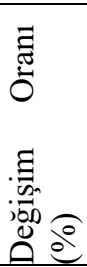 } & RfD-2040 & -100 & 3493 & - & -100 & 3503 & - \\
\hline & RfD-2070 & -98 & 3434 & - & -100 & 3493 & - \\
\hline & RfD-2099 & -94 & 3281 & - & -51 & 1789 & - \\
\hline & $2040-2070$ & 925 & -2 & - & 13900 & 0 & - \\
\hline & $2040-2099$ & 3392 & -6 & - & 3229900 & -48 & - \\
\hline & 2070-2099 & 241 & -4 & - & 22971 & -47 & - \\
\hline
\end{tabular}

\section{Kayın (Fagus) Birlikleri}

\subsection{Kayın-Göknar (Fagus - Abies) Egemen Birliği}

Yaklaşık $8 \mathrm{~km}^{2}$ alana sahip Kayın-Göknar ormanları Kazdağı'nın kuzey yamacında 488m - 1425m arasında, güney yamacında ise, 1106m - 1431m arasında yayılır (Hepbilgin \& Koç, 2019a). KayınGöknar ormanlarında Macar meşesi de (Q.frainetto) yer yer bulunur (Hepbilgin, 2019c). Kayın-Göknar ormanları Erinç iklim sınıflandırmasına göre, Referans Döneminde (RfD) çok nemli iklim etkisi altındadır (Tablo 27). Bununla birlikte, 2099 yllına doğru sahada çok nemli iklim etkisini kaybederek nemli iklim egemen olmuş, yarı nemli iklim etki alanı da az da olsa genişlemiştir (Tablo 27). Kötümser senaryoda (RCP 8.5) da değişim benzer, fakat daha belirgindir (Tablo 27).

Tablo 27. Kayın - Göknar (Fagus - Abies) Egemen Birliğinde Alansal İklim Değișimleri

\begin{tabular}{|c|c|c|c|c|c|c|c|}
\hline \multicolumn{5}{|c|}{ FagAbi $(K n G)$} & \multirow{2}{*}{\multicolumn{3}{|c|}{ RCP 8.5}} \\
\hline \multicolumn{5}{|c|}{$\mathrm{RCP} 4.5$} & & & \\
\hline \multicolumn{3}{|c|}{ Y1l Aralığgl $\mid$ Çok Nemli } & Nemli & Yar1 Nemli & Çok Nemli & Nemli & Yarı Nemli \\
\hline \multirow{4}{*}{$\mathrm{km}^{2}$} & $1970-2000(\mathrm{RfD})$ & 6,22 & 1,10 & 0,13 & 6,22 & 1,11 & 0,12 \\
\hline & $2016-2040$ & 5,54 & 1,64 & 0,27 & 6,20 & 1,03 & 0,14 \\
\hline & $2041-2070$ & 3,01 & 4,02 & 0,43 & 5,13 & 1,95 & 0,36 \\
\hline & $2071-2099$ & 0,12 & 6,78 & 0,56 & - & 6,62 & 0,84 \\
\hline \multirow{3}{*}{ 泀 } & RfD-2040 & -11 & 49 & 116 & 0 & -7 & 17 \\
\hline & RfD-2070 & 301 & 402 & 43 & 513 & 195 & 36 \\
\hline & RfD-2099 & -98 & 516 & 344 & -100 & 496 & 600 \\
\hline \multirow{3}{*}{ 四 } & $2040-2070$ & -46 & 145 & 57 & -17 & 89 & 157 \\
\hline & 2040-2099 & -98 & 312 & 106 & -100 & 543 & 500 \\
\hline & $2070-2099$ & -96 & 68 & 31 & -100 & 239 & 133 \\
\hline
\end{tabular}

\subsection{Kayın-Karaçam (Fagus - Pinus nigra) Egemen Birliği:}

Kazdağı doğal orman alanı içerisinde yaklaşık $14 \mathrm{~km}^{2}$ alana sahip Kayın-Karaçam ormanları (KnÇk), Kazdağı kuzey yamacında 414m - 1278m arasında; güney yamacında ise 599m - 1421m arasında yayılmaktadır (Hepbilgin \& Koç, 2019a). Erinç iklim sınıflandırmasına göre, Referans Döneminde Kayın-Karaçam ormanlarının büyük bölümü nemli iklim, yaklaşık $4 \mathrm{~km}^{2}$ 'si çok nemli iklim ve daha küçük bir alanı yarı nemli iklim etkisi altındadır (Tablo 28). Tablodaki iklim değişim deseni incelendiğinde, Kayın-Karaçam ormanlarında 2071-2099 döneminde her iki senaryoya göre de nemli iklim ve yarı nemli iklimin hakim olduğu görülmektedir (Tablo 28). 
Tablo 28. Kayın-Karaçam (Fagus - Pinus nigra) Egemen Birliğinde Alansal İklim Değişimleri

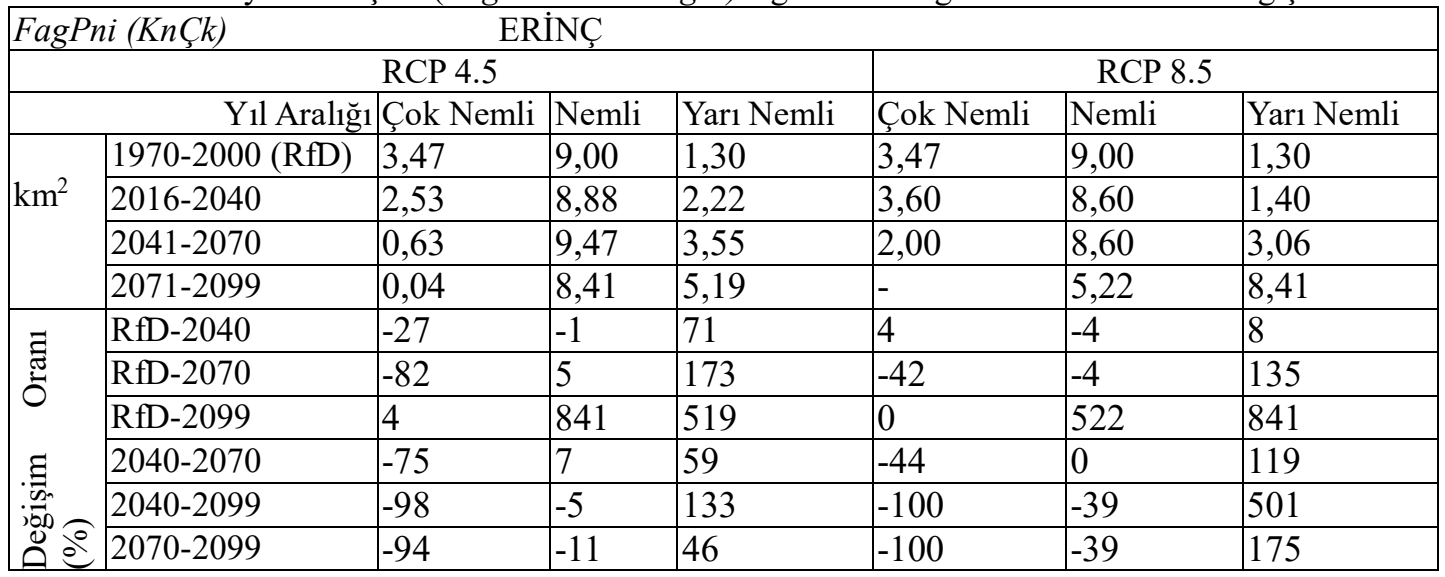

Emberger iklim sınıflandırmasına göre Kayın-Karaçam ormanlarında Az Yă̆ışlı Akdeniz iklimi egemendir (Tablo 29). Bununla birlikte, 2016-2040 periyodunda ve 2099 sürecinde sahada Yağ lşl Akdeniz ikliminin egemen olduğu görülmektedir (Tablo 29). Kötümser senaryoda ise benzer ve daha belirgin bir durum görülmektedir (Tablo 29).

Tablo 29. Kayın-Karaçam (Fagus - Pinus nigra) Egemen Birliğinde Alansal İklim Değişimleri

\begin{tabular}{|c|c|c|c|c|c|c|c|}
\hline \multicolumn{5}{|c|}{ FagPni (KnÇk) } & & & \\
\hline \multicolumn{5}{|c|}{ RCP 4.5} & \multicolumn{3}{|c|}{ RCP 8.5} \\
\hline & Y1l Aralığ & AzYağAkd & YağAkd & YarıKurAkd & AzYağAkd & YağAkd & YarıKurAkd \\
\hline \multirow{4}{*}{$\mathrm{km}^{2}$} & 1970-2000 (RfD) & 9,80 & 3,75 & - & 9,80 & 3,75 & - \\
\hline & $2016-2040$ & - & 13,60 & - & - & 13,60 & - \\
\hline & 2041-2070 & - & 13,60 & - & - & 13,60 & - \\
\hline & 2071-2099 & 0,00 & 13,60 & - & 1,16 & 12,40 & - \\
\hline \multirow{3}{*}{ 离 } & RfD-2040 & -100 & 263 & - & - & 263 & - \\
\hline & RfD-2070 & -100 & 263 & - & - & 263 & - \\
\hline & RfD-2099 & -100 & 263 & - & - & 231 & - \\
\hline \multirow{3}{*}{ 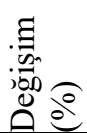 } & $2040-2070$ & - & 0 & - & - & - & - \\
\hline & 2040-2099 & - & 0 & - & - & - & - \\
\hline & $2070-2099$ & - & 0 & - & - & - & - \\
\hline
\end{tabular}

\section{Kestane (Castanea) Birlikleri}

8.1 Kestane-Karaçam (Castanea - Pinus nigra) Egemen Birliği:

Kazdağı'nda yaklaşık $7 \mathrm{~km}^{2}$ alana sahip Kestane-Karaçam ormanlarında yer yer meşe'ler de gözlenir. Kestane-Karaçam ormanları, Kazdağı'nın yalnızca kuzey yamacında, 489m-1192m arasında yayılır. (Hepbilgin \& Koç, 2019a). Kestane-Karaçam ormanlarının neredeyse tamamında Erinç iklim siniflandırmasına göre nemli iklim egemendir (Tablo 30). Bununla birlikte, 2071-2099 dönemine gelindiğinde, sahada yarı nemli ikliminin egemen olduğu gözlenmektedir (Tablo 30). Kötümser senaryoda da durum benzer ve daha belirgindir (Tablo 30). 
Tablo 30. Kestane-Karaçam (Castanea - Pinus nigra) Egemen Birliğinde Alansal İklim Değişimleri

\begin{tabular}{|c|c|c|c|c|c|c|c|}
\hline \multicolumn{5}{|c|}{ CasPni (KsÇk) } & & & \\
\hline \multicolumn{4}{|c|}{ RCP 4.5} & & \multicolumn{3}{|c|}{ RCP 8.5} \\
\hline & Y1l Aralığ1 & Çok Nemli & Nemli & Yar1 Nemli & Çok Nemli & Nemli & Yarı Nemli \\
\hline \multirow{4}{*}{$\mathrm{km}^{2}$} & $1970-2000$ (RfD) & 0,48 & 5,12 & 0,81 & 0,48 & 5,12 & 0,81 \\
\hline & $2016-2040$ & 0,01 & 4,50 & 1,90 & 0,01 & 4,90 & 0,98 \\
\hline & 2041-2070 & - & 3,02 & 3,30 & - & 3,83 & 2,57 \\
\hline & 2071-2099 & - & 1,64 & 4,70 & - & 0,69 & 5,71 \\
\hline \multirow{3}{*}{ 矛 } & RfD-2040 & -97 & -12 & 134 & -98 & -4 & 21 \\
\hline & RfD-2070 & - & -41 & 306 & - & -25 & 217 \\
\hline & \begin{tabular}{|l|} 
RfD-2099 \\
\end{tabular} & - & -68 & 478 & |- & -87 & 605 \\
\hline \multirow{3}{*}{ 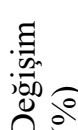 } & $2040-2070$ & - & -33 & 74 & - & -22 & 162 \\
\hline & \begin{tabular}{|l|}
$2040-2099$ \\
\end{tabular} & - & -64 & 147 & - & -86 & 483 \\
\hline & $2070-2099$ & - & -46 & 42 & - & -82 & 122 \\
\hline
\end{tabular}

Emberger iklim sınıflandırmasına ve her iki senaryo sonuçlarına göre de, Referans Dönemde (RfD) Kestane-Karaçam ormanlarında Az Yağışlı Akdeniz iklimi egemendir (Tablo 31). Ancak 2016-2040 döneminden itibaren tüm projeksiyon dönemlerinde Yağış̧l Akdeniz iklimi egemen olmuştur (Tablo 31).

Table 31. Kestane-Karaçam (Castanea - Pinus nigra) Egemen Birliğinde Alansal İklim Değişimleri

\begin{tabular}{|c|c|c|c|c|c|c|c|}
\hline \multirow{2}{*}{\multicolumn{5}{|c|}{ CasPni (KsÇk) }} & \multirow{2}{*}{\multicolumn{3}{|c|}{ RCP 8.5}} \\
\hline \multicolumn{2}{|c|}{ RCP 4.5} & & & & & & \\
\hline & Y1l Aralığ & AzYağAkd & YağAkd & YarıKurAkd & AzYağAkd & YağAkd & YarıKurAkd \\
\hline \multirow{4}{*}{$\mathrm{km}^{2}$} & 1970-2000 (RfD) & 5,83 & 0,58 & - & 5,83 & 0,58 & - \\
\hline & 2016-2040 & - & 6,41 & - & - & 6,41 & - \\
\hline & 2041-2070 & - & 6,41 & - & - & 6,41 & - \\
\hline & 2071-2099 & - & 6,41 & - & 0,90 & 5,51 & - \\
\hline \multirow{6}{*}{\begin{tabular}{|l} 
壳 \\
On
\end{tabular}} & RfD-2040 & - & 968 & - & - & 1003 & - \\
\hline & RfD-2070 & - & 968 & - & - & 1005 & - \\
\hline & RfD-2099 & - & 968 & - & -85 & 853 & - \\
\hline & $2040-2070$ & - & 0 & - & - & 0 & - \\
\hline & 2040-2099 & - & 0 & - & - & -14 & - \\
\hline & 2070-2099 & - & 0 & - & - & -14 & - \\
\hline
\end{tabular}

\section{Sonuç}

Kazdağı'nın doğal orman alanı içerisindeki yaygın saf ağaç toplulukları ve egemen birliklerinin iklim değişikliği projeksiyonu iyimser ve kötümser senaryolarına göre alansal olarak nasıl etkilendiğini ele alan bu çalşsmada, genel olarak nemli veya çok nemli iklim koşullarının egemen olduğu alanların yerini yarı nemli ve nispeten yarı kurak iklim koşullarına bıraktığı sonucuna ulaşılmıştır. Diğer bir deyişle, Kazdağ yaygın saf ağaç topluluklarında ve egemen birlik alanlarında nemli ve çok nemli iklim tipleri önemli oranlarda alan kaybederken, yarı nemli ve yarı kurak iklim tipleri alan kazanmışıır. Tüm sonuçlar kötümser senaryoda genel olarak benzer olmakla birlikte biraz daha yüksek değişim sonuçları vermiştir. Yine, genel olarak iklim tiplerindeki en büyük değişimin ilk projeksiyon periyodunda gerçekleştiği söylenebilir.

Erinç İklim Sınıflandırması sonuçlarına göre, referans dönemde Karaçam-Kestane; Karaçam-Meşe; Karaçam-Kızılçam; Meşe-Karaçam ve Kestane-Karaçam ormanlarında nemli iklim hakim iken sonraki dönemlerde yarı nemli iklim koşullarına doğru bir değişim elde edilmiştir.

Kızılçam-Karaçam ormanlarında referans dönemde yarı nemli iklim egemen iken yarı kurak iklim gelişmeye başlamıştır.

Kızılçam-Meşe ormanlarında çok nemli ve nemli iklim egemenliğini kaybederek sahada yarı nemli iklim koşulları egemen olmuştur.

Kızılçam-Diğer Yapraklılar ormanlarında yarı nemli iklim koşulları egemen iken son projeksiyon döneminde yarı kurak iklim koşulları gelişmeye başlamıştır.

Meşe ormanlarında referans dönemde nemli ve yarı nemli iklim koşulları hakim iken, dönemler 
sürecinde yarı nemli iklim alan kaybederek yarı kurak iklim alanı genişlemiş̧ir.

Karaçam ormanları referans dönemde çok nemli, nemli ve yarı nemli iklim koşulları altında iken, 2099 yılına doğru yarı nemli iklim alanı genişlemiştir.

Kızılçam ormanlarının tümünde yarı nemli iklim egemen iken, 2099 yılına doğru sahada yarı kurak iklim koşulları gelişmeye başlamıştır.

Kayın-Göknar ormanları referans dönemde çok nemli iklim koşulları altındadır, projeksiyon dönemleri sürecinde nemli iklim egemendir; bununla birlikte, yarı nemli iklim etki alanını genişletmektedir.

Kayın-Karaçam ormanları referans dönemde çok nemli iklim ve nemli iklim etkisi altında iken çok nemli iklim koşulları tamamen ortadan kalkarak sahaya nemli ve yarı nemli iklim hakim olmuştur.

Emberger İklim Sınıflandırması sonuçlarına göre, Karaçam-Kestane; Karaçam-Kayın; Karaçam-Meșe; Karaçam-Kızılçam; Kızılçam-Diğer Yapraklılar; Kızılçam ormanlarında genel olarak 2040 yılına gelindiğinde Az Yağışlı Akdeniz iklim koşulları ortadan kalkmış, Yağışlı Akdeniz iklimi egemen olmuştur.

Karaçam-Maki; Kızılçam-Karaçam ormanlarında Az Yağışlı Akdeniz ikliminden Yağışı Akdeniz iklimine geçiş elde edilmiştir.

Kızılçam-Meşe ormanlarında Az Yağışıı Akdeniz iklimi etkiliyken ilk iki projeksiyon döneminde Yağışı Akdeniz iklimi egemen olmuş, son dönemde (2071-2099) yeniden Az Yağışlı Akdeniz iklimi etki alanine genişletmiştir.

Meşe ormanlarında referans döneminde Az Yağışı Akdeniz iklimi egemen iken, tüm projeksiyon dönemlerinde Yağışlı Akdeniz İklimi egemen olmuştur.

Karaçam ormanlarında da 2040 yılına gelindiğinde sahanın tamamında Yağışılı Akdeniz iklimi koşulları egemen olmuş, sonraki dönemlerde de egemenliğini sürdürmüştür.

Meşe-Karaçam; Kayın-Karaçam ve Kestane-Karaçam ormanlarında referans dönemde Az Yağışlı İklim egemen iken, sonraki dönemlerde Yağışlı Akdeniz iklimi egemen olmuştur.

Ağaç türlerinin sıcaklık artış ve azalışlarına karşı toleransları genellikle yüksek olsa da iklimin en önemli iki elemanı olan sıcaklık ve yağışın değerlendirildiği iklim sınıflandırmalarına göre iklim tiplerindeki değişimlerin uzun dönemde önemli ekolojik sorunlar doğuracağı açıktır. Bu çalışma ile elde edilen sonuçların Kazdağı doğal orman alanı içerisindeki ağaç türlerine yönelik yapılacak sonraki daha ayrıntılı ekocoğrafik çalışmalar için önemli bir altlık/kaynak teşkil edeceği beklenmektedir.

\section{Kaynakça}

Akman, Y. 1990. İklim ve Biyoiklim. Palme Yayın Dağıtım,1. Basım, Ankara.

Boulangeat, I., et al. (2014). Anticipating the Spatio-Temporal Response of Plant Diversity and Vegetation Structure to Climate and Land Use Change in a Protected Area. Ecography 37: 12301239 .

Buras, A., \& Menzel, A. (2019) Projecting Tree Species Composition Changes of European Forests for 2061-2090 unders RCP 4.5 and RCP 8.5 Scenarios. Frontiers in Plant Science, 9 doi:10.3389/fpls.2018.01986

Cannone, N., et al. (2014). Ecological Responses of Plant Species and Communities to Climate Warming: Upward Shift or Range Filling Processes? Climatic Change 123, 2014, 201-214

Erinç, S. 1984. Klimatoloji ve Metodları. Deniz Bilimleri ve Coğrafya Enstitüsü Yayınları, İstanbul.

Hepbilgin, B., \& Koç, T. (2019a). Spatial Differentiation in Tree Formation Distribution of Kaz Mount. $1^{\text {st }}$ International Symposium on Biodiversity Research. [Online] Available: http://isbr2019.comu.edu.tr/sempozyum-kitabi.html

Hepbilgin, B., \& Koç, T. (2019b). Projected Effects of Climate Change on the Tree Formation of Kazdağ 1 (mt. Ida) and Its Vicinity. International Journal of Geography and Geography Education, 39: 311-327.

Hepbilgin, B. (2019c) Kazdağı Ormanlarında Birliklere Göre Eğim ve Bakı Analizi, Uluslararası Sosyal Araştırmalar Dergisi, 12: 230-247

77 I P a g e

www.iiste.org 
Hepbilgin, B., \& Koç, T. (2018). Bölgesel Sıcaklık ve Yağı̧̧ Verilerine Göre Kazdağı ve Yakın Çevresinin İkliminde Öngörülen Değişiklikler (2000-2099), e-Marmara Coğrafya Dergisi (elektronik) 37, 253-270.

Koç, D.E \& İkiel, C. (2017). Trakya'da Vejetasyon Süreleri ve Değişimleri. International Journal of Human Sciences, 14(3): 2326-2344. doi:10.14687/jhs.v14i3.4726

Koo, A., et al. (2017). Potential Climate Change Effects on Tree Distributions in the Korean Peninsula: Understanding Model \& Climate uncertainties. Ecological Modelling 353: 17-27.

Lin, W., et al. (2014). Expansion of Protected Areas under Climate Change: An Example of Mountainous Tree Species in Taiwan. Forests 5: 2882-2904

Mert, A. et al. (2016). Changing the Potential Distribution of Turkey Oak (Quercus cerris L.) under Climate Change in Turkey. Pol. J. Environ. Stud. 25, 1-6. Doi:10.15244/pjoes/622300

Şar, T. et al. (2018) İklim Değişikliği Senaryolarına göre İç Batı Anadolu Bölümü’nde Vejetasyon Dönemi. 8. Türkiye Kuvaterner Sempozyumu, 2-5 Mayıs 2018, İstanbul. ISBN: 978-605-815781-1

Zeydanlı, U. et al. 2010. İklim Değişikliği ve Ormancılık: Modellerden Uygulamaya. Ankara. Doğa Koruma Merkezi. 